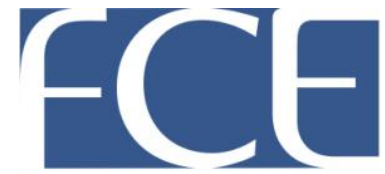

Facultad de

Ciencias Económicas

UNIVESSIDAD NACIONAL DE LA PLATA

\title{
MAESTRÍA EN GESTIÓN TURÍSTICA
}

Tema:

Normas de calidad aplicables al Sector de Alojamientos turísticos, necesidad de armonización de la legislación aplicable; Caso: Buenos Aires

Trabajo Científico libre para la obtención del grado de Magíster en Gestión Turística

Facultad de Ciencias Económicas

Universidad Nacional de La Plata

Director de Tesis:

\section{Presentado por maestrando:}

Carlos Javier Ontivero

Domicilio 525 bis Nro 1620

Tolosa- Ciudad de La Plata.-

Prof. Dr. Alejandro Magliano

Fecha de entrega: 18 de Octubre de 2011.- 
"Adoptar la nueva filosofía. Estamos en una nueva era económica, los gerentes occidentales deben despertar al reto, deben aprender sus responsabilidades y tomar el liderazgo hacia el cambio".

Edward Deming 


\section{Agradecimientos}

Esta obra está dedicada a la Madre Tres Veces Admirable de Schoenstatt, a mi mamá que me apoyo durante todo el curso de la maestría y siempre, en toda mi vida, estuvo a mi lado; también quiero agradecer a mis hermanos por su apoyo incondicional; a mi novia, Silvina Herrero, por su apoyo incondicional me dio fuerzas para realizar este trabajo; al Dr. Carlos José Sánchez por toda su ayuda.

También quisiera expresar mi agradecimiento a la Cdora. Leandra Toschi por su incondicional apoyo a este trabajo; a todos mis amigos de la secundaria y de aikido, en especial a los profesores Daniel Collazo y Pablo Veneziano que a través de sus enseñanzas me ayudaron emprender el camino de la armonización que me ayudo a la elaboración del presente trabajo.

También quiero agradecer al Instituto de Derecho Comercial del Colegio de Abogados de La Plata en especial a los Dres. Garobbio y Cruset.-

También quiero agradecer especialmente a mi director de tesis, el Dr. Alejandro Magliano, al consultor Guillermo Gesualdo, al Ing. Alfredo Escalona, al Dr. Avelino Blasco y a la Dra. Cristina Iglesias y a la Lic. Mariela Wagner y al Dr. Gonzalo Casanova Ferro porque sin su ayuda esto no hubiera sido posible. 


\section{Contenido}

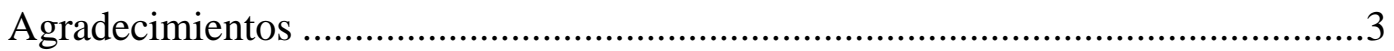

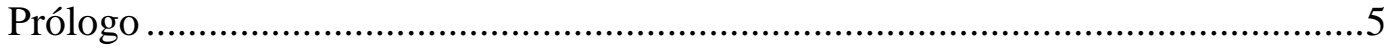

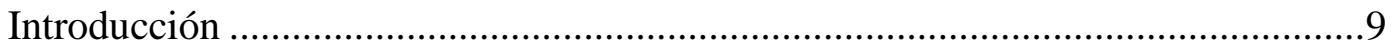

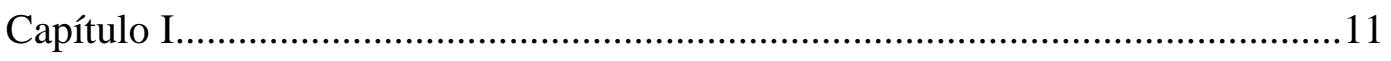

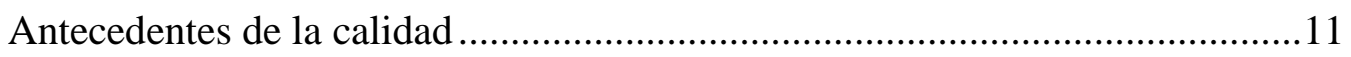

Introducción a la calidad turística .................................................................13

Antecedentes de la normativa hotelera vigente.............................................15

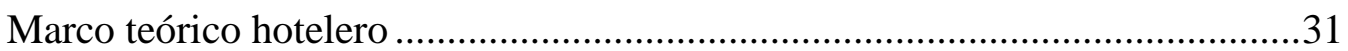

Relevamiento, sistematización y análisis de la normativa vigente a nivel

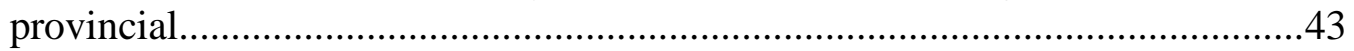

Marco normativo internacional (España) .....................................................44

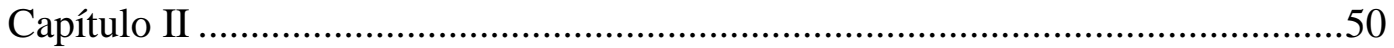

Normas de calidad (normas voluntarias) y normas jurídicas (normas

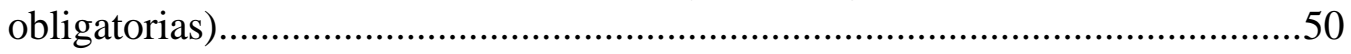

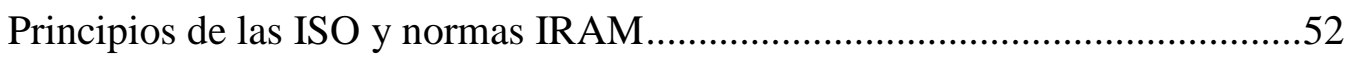

Los sistemas de gestión integrada de la calidad.............................................56

Modelo de un SGC basado en procesos .......................................................56

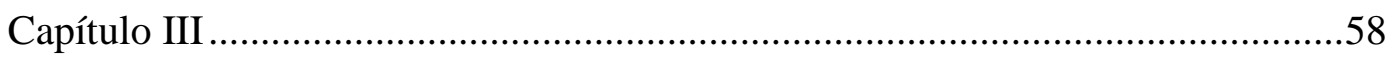

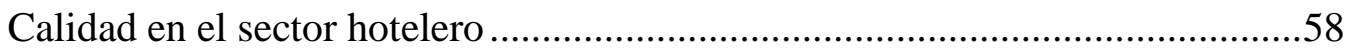

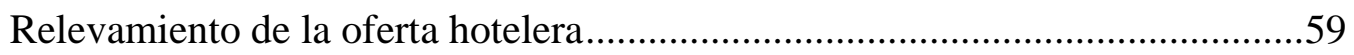

Sistema de gestión de calidad: normas ISO ..................................................67

Distintas normas de calidad (comparación) ..................................................69

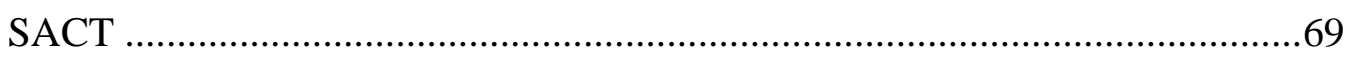

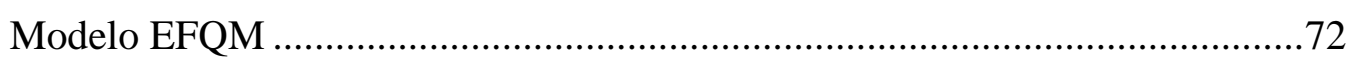

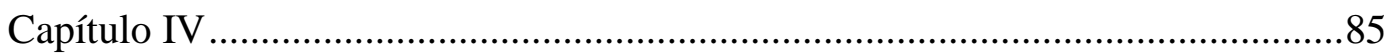

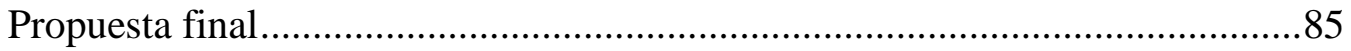

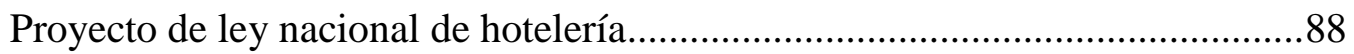

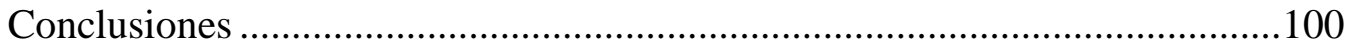

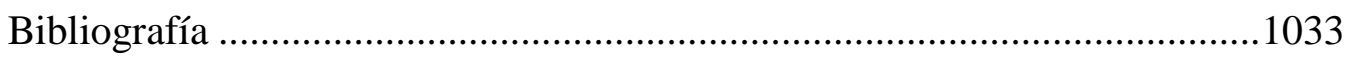

Anexo I: Encuesta al sector hotelero para tesis..........................................1066

Anexo II: Encuesta al Sector hotelero para Tesis .......................................1099 


\section{Prólogo}

En virtud de la trascendencia de la temática, en esta investigación tiene como

\section{Objetivo General}

Estudiar las pautas y criterios de calidad que se practican en la actualidad y aquellas que deberían incorporar en el marco regulatorio, con el fin de impulsar la competitividad, para la consolidación de destinos turísticos atractivos, que estimulen a la demanda con carácter sostenido en el tiempo y que contribuyan a la creación de empleo capacitado y oferta calificada, facilitando el desarrollo económico.

\section{Objetivos específicos}

El objetivo específico es desarrollar una propuesta normativa, de aplicación nacional para el sector de alojamientos turísticos, que contemple todos los aspectos relacionados con la Calidad, estableciendo pautas para la habilitación, categorización y control de los mismos.

\section{Hipótesis}

- La necesidad de una normativa en cuanto a los establecimientos de hospedaje conforme a los cambios que se produjeron en el contexto social, incorporando a aquellos que han quedado por fuera de la normativa vigente en la actualidad.

- Cada vez más en el mundo globalizado, el acceso a la información es más inmediato, por lo que es necesario un marco normativo que asegure la calidad en los establecimientos de hospedaje.

\section{Metodología a emplear}

Para la realización del diagnóstico, se tomarán diversas fuentes y métodos: 


\section{Revisión de Bibliografía Secundaria:}

En primera instancia, se revisará bibliografía teórica sobre Regulación de Alojamientos Turísticos existente a nivel internacional y también nacional.

\section{Datos Estadísticos y marco legislativo:}

Para realizar el diagnóstico sobre el marco jurídico en materia de Alojamientos

Turísticos vigentes, se utilizarán las siguientes fuentes y métodos:

- Información sobre normativa vigente generados a partir de búsqueda en bases de datos legislativos nacionales

- Datos Estadísticos relativos a Cantidad y Tipo de Alojamiento Hotelero y Para Hotelero, provistos por los organismos de turismo provinciales, INDEC y

\section{SECTUR}

- Ordenanzas y leyes provistas por los organismos públicos provinciales

- $\quad$ Entrevistas en profundidad a personas vinculadas a esta industria para determinar el estado actual del sector hotelero.

A partir de la bibliografía secundaria se realizará la descripción del marco jurídico vigente para el sector Alojamientos Turísticos.

Para realizar el análisis comparativo de la normativa vigente con la de otras provincias y de otros países mercados objetivos de la región se analizarán individualmente las normas provinciales identificando los siguientes parámetros:

Año de sanción, organismo de aplicación, criterio de clasificación, clases de establecimientos, categorización, servicios obligatorios, menciones a la calidad, preservación del medio, recursos humanos, modalidad novedosa, habilitaciones, normas de seguridad, accesibilidad, idiomas requeridos, régimen de sanciones, participación del Sector Privado.

Con la información suministrada por los responsables de los establecimientos de alojamiento y de los organismos públicos se elaborarán los resultados preliminares 


\section{Datos cualitativos:}

Se realizarán entrevistas en profundidad a personas claves dentro de la función pública y privada, tales como propietarios de alojamientos turísticos en todas sus modalidades, funcionarios de turismo, directores de área y otros funcionarios relacionados directamente con la temática en análisis.

El período de análisis del marco jurídico estará enmarcado entre los años 1970 - 2008 tomando como referencia la sanción de la ley 18828 en el año 1970 y su decreto reglamentario 1818 del año 1976 que en el nivel nacional fija el marco legal para los establecimientos hoteleros en la República Argentina.

\section{Capítulo 1}

En el primer capítulo de este trabajo de investigación se determinará el concepto, la evolución y la normalización de la calidad y la calidad de servicio, determinando el grado de implementación y avance que ha tenido especialmente en los servicios.

\section{Capítulo 2}

Elaboración de un Cuadro de Situación sobre el estado actual del segmento de alojamientos turísticos, a través de:

1. Relevamiento, sistematización y análisis de la totalidad de la normativa vigente a nivel provincial y en los principales destinos turísticos de la Provincia en materia de alojamientos turísticos;

2. Realización del análisis comparativo de la normativa vigente en la Provincia de Buenos Aires y la Ciudad de Buenos Aires;

3. Comparación de la normativa vigente con la de otras provincias y de otros países de la región;

4. Elaboración de encuestas y realización de entrevistas en profundidad a actores locales.

\section{Capítulo 3}


En el capítulo se analizará la importancia de la calidad para el sector hotelero, destacando su prioridad como ventaja competitiva dentro del sector y la importancia que se otorga como necesidad para asegurar las cifras de crecimiento que está teniendo.

Para ello se efectuará:

1. Una revisión de la literatura de los trabajos de investigación que estudian la medición de la calidad de servicio en el sector hotelero tomando como referente al cliente, debido a que éste quien determina la calidad del servicio recibido.

2. Un relevamiento de la oferta de alojamiento siguiendo las fuentes de datos estadísticos provinciales y nacionales

3. Análisis de indicadores, parámetros y criterios determinantes de las categorías y clases, tenidos en cuenta en la clasificación y categorización de alojamientos turísticos contenidos en marcos normativos modernos y en normas de calidad aplicadas en destinos competitivos, así como de los lineamientos fijados en el Plan Federal Estratégico de Turismo Sustentable

4. Se tomará una muestra representativa de los establecimientos con el fin de indagar cuáles son los aspectos de gestión que, según la opinión de los expertos directivos en gestión de alojamientos turísticos, llevarán a los establecimientos de alojamiento turístico en Buenos Aires a mejorar su calidad de servicio

\section{Propuesta - Conclusiones}

Identificación y descripción preliminar de los parámetros y criterios determinantes de la clasificación y categorización de los establecimientos provinciales, sobre los cuales debería sustentarse un nuevo marco normativo de la actividad, a partir de los resultados del análisis precedente.- 


\section{Introducción}

Desde la década de los 90 se ha producido un notable incremento de las plazas de alojamiento turístico tanto en la ciudad como en la provincia Bs. As., al tiempo que se ha diversificado la tipología de alojamientos de acuerdo a la variación y especialización en la segmentación de la demanda. Han surgido nuevos tipos de hospedaje dado el surgimiento de diferentes motivaciones de los turistas, que se caracterizan por su nivel de información, conocimiento y un alto grado de exigencia. Tal es el caso de los albergues, hostales, bed \& breakfast, hoteles boutique, etc. que han surgido con fuerza en la ciudad en respuesta a nuevas formas de turismo.

En el nuevo escenario que se presenta, no sólo se debe priorizar la promoción del destino, sino la idealización de los visitantes por medio de reglas claras en cuanto a las expectativas que traen. Por ello es que se deben concebir estrategias basadas en la generación de oferta de productos y servicios de calidad, además de la potenciación del sector en torno a criterios de respeto ambiental y cultural; el sector de alojamientos turísticos presenta unos rasgos propios ya que se considera un producto-servicio pero que está altamente influida por las opiniones y valoraciones hechas por los clientes. Este hecho implica la necesidad de establecer unos criterios específicos que incluyen, entre otros, aspectos relacionados con la calidad de servicio.

En la C. A. B. A. Los alojamientos turísticos son regulados por la Ordenanza $\mathrm{N}^{\circ}$ 36.136 que desde el año 1980 regula todo lo concerniente a los alojamientos turísticos hoteleros y extra hoteleros. Es así, que en el momento de la sanción de la legislación vigente, sólo se tenía en cuenta para la categorización de los establecimientos cuestiones inherentes a la infraestructura omitiendo aspectos relevantes como la calidad del servicio prestado de acuerdo a la tendencia internacional Por consiguiente que esta normativa resulta anacrónica de acuerdo a los nuevos estándares que deben regir para esta actividad.

El cambio en el escenario turístico internacional que repercute en nuestro país obliga a adaptar la normativa sobre la base de criterios más flexibles, dinámicos y modernos en pos de un crecimiento sostenido y planificado de la actividad turística... 
El concepto de calidad tiene una amplia aceptación en la cultura universal en nuestros días, asentándose en la economía de la empresa como un valor económico y competitivo y determinante en las conductas y de las distintas decisiones que toman los agentes económicos. A modo de ejemplo, normas como las ISO y los sellos de calidad establecidos en diferentes países, tienen en cuenta la satisfacción del cliente, la capacitación y motivación del personal, el seguimiento de procedimientos operativos, la adhesión al cuidado del medioambiente, etc.

El sector de alojamientos turísticos resulta imprescindible para el desarrollo y cualificación del sector, y por ende requiere de una especial atención por parte de las autoridades que debe acompañar su crecimiento con políticas y normas que no obstaculicen su desarrollo al tiempo que debe arbitrar los mecanismos necesarios para representar los intereses de los usuarios.

Resulta imprescindible que la autoridad de aplicación de las normas disponga las capacidades y las competencias necesarias para fortalecer su función y su rol en cuanto a la habilitación, inspección, fiscalización, control a través de un proceso dinámico y flexible acorde a la jerarquía que debe tener el organismo responsable turístico tanto de la Ciudad cómo de la Provincia de Bs. As.

Las propias características de los establecimientos de alojamiento turístico implican la convivencia de aspectos tangibles (instalaciones) y aspectos intangibles (el servicio). La dependencia de los aspectos tangibles implica una elevada inversión en costos fijos, mientras que los aspectos intangibles significan una elevada intensidad en mano de obra. El establecimiento hotelero se concibe como parte de la experiencia global que es el turismo y, por tanto, existe una elevada interrelación entre todos los agentes que participan de esa experiencia.

La situación actual del sector de alojamientos turísticos en Buenos Aires está marcada por la incertidumbre derivada de las propias características de la demanda y por las dificultades generadas tanto por la reciente crisis internacional como por las crisis locales (conflictos gremiales, pandemia, dengue) . 
Este trabajo pretende, partiendo de la definición de calidad de servicio, profundizar en la opinión del directivo y del experto hotelero, como agentes que toman las decisiones y cuyas consecuencias determinarán el tipo de gestión que se desarrolla en la empresa turística, y que serán definitivas para que el cliente perciba y determine el grado de calidad de servicio del establecimiento.

\section{Capítulo I}

\section{Antecedentes de la calidad}

Se puede establecer la aparición del concepto moderno de la calidad ${ }^{1}$ en torno a la década de 1920, en Estados Unidos , impulsada por grandes compañías como Ford Motor Company, American Telephone \& Telegraph (ITT) ,Western Electric, etc. que comienzan a implantar el criterio de calidad de diversas formas.

En este periodo se desarrolla el Control Estadístico de Procesos ( SPC) en manos del considerado padre de la calidad,Walter A. Shewhart, quien fue el primero en realizar estudios sistemáticos sobre la calidad desarrollando métodos estadísticos. En el año 1924 comenzó a implantar, en la Bell Telephone Company, el Control Estadístico de Procesos y consiguió reducir el porcentaje de defectos en la empresa.

La Segunda Guerra Mundial (1939-1945) constituyó el detonante fundamental parar un notable desarrollo del Control Estadístico de Procesos, así como del interés general por todos los temas relacionados con la calidad. Durante esta época, importantes maestros de la calidad como Walter E. Deming y Joseph M. Juran participan y desarrollan el Programa de Gestión de la Calidad. En este período del conflicto bélico se avanza de forma considerable en los diferentes aspectos de la calidad.

1 Calidad en el servicio y satisfacción al cliente. Dra. Cristina Iglesias (Universidad de Quilmes)Pags. 17-21 
También en esta época, Armand V. Feigenbaum comienza a desarrollar un concepto nuevo: el control de la calidad total. En él se incluye una gestión de la calidad más extensa que abarca todas las áreas de la empresa y que persigue la satisfacción plena de los clientes. Se puede considerar como el origen de lo que hoy se denomina la Gestión de la Calidad Total (G. C. T).

Una vez finalizado el conflicto bélico mundial, se produce un trasvase de ideas y conceptos hacia Japón. Los japoneses aprenden las técnicas de Control Estadístico de Procesos adaptándolas de forma rápida, en principio como mera inspección , estableciendo tolerancias de la calidad en los productos , para pasar, en una segunda fase, a controlar el proceso evitando los fallos en el producto final. A ello contribuyó una serie de conferencias y seminarios que fueron impartidos en Japón sobre esta temática por los maestros Deming y Juran.

Coincidiendo con el auge de la calidad en Japón, la industria americana sufrió una caída apreciable a comienzos de la década de 1950. La causa principal fue el exceso de confianza, lo que provocó un estancamiento de la evolución. Se abandonaron las técnicas de calidad debido a la falta de competidores cualificados y sólo se puso interés en producir y vender bienes para abastecer al mercado mundial. Este fenómeno coincide con un aumento paulatino de las prestaciones, fiabilidad y calidad de los productos japoneses, más preocupados por la mejora continua y por una constante evolución, alentados por las ideas que les inculcaron Deming y Juran. Con este panorama, Japón aprovecha el encasillamiento americano para lanzarse a su conquista.

Durante la década de 1980 la calidad experimenta una evolución en la industria americana y comienza a considerarse un elemento estratégico fundamental.

En la década de 1960, Phillip B. Crosby lanza el concepto de cero defecto, aplicándolo en la International Telephone \& Telegraph (ITT), donde trabajo como director de calidad, logrando reducir gran cantidad de inspecciones. A través de de un programa de 14 puntos para la gestión de la calidad introdujo el programa de mejora tratando de concientizar a las empresas para que centraran sus esfuerzos en la necesidad de obtener calidad. El 
objetivo consistía en suprimir gran parte de las inspecciones haciendo las cosas bien desde el principio ${ }^{2}$.

En su programa de trabajo, la OMT entiende la calidad del turismo como "el resultado de un proceso que implica la satisfacción de todas las necesidades, exigencias y expectativas legítimas de los consumidores respecto a los productos y servicios, a un precio aceptable, de conformidad las condiciones contractuales mutuamente aceptadas y con los factores subyacentes que determinan la calidad tales como la seguridad, la higiene, la accesibilidad, la transparencia, la autenticidad y la armonía de una actividad turística preocupada por su entorno humano y natural".[Definición preparada y modificada por el Comité de Apoyo a la Calidad en su sexta reunión (Varadero, (Cuba) 9 y 10 de mayo de 2003).

Existen cuatro etapas bien definidas a lo largo de la evolución de la calidad: inspección, control de la calidad, aseguramiento de la calidad, calidad total y excelencia.En la primera etapa, la calidad era entendida más bien como inspección final del producto, al objetivo de adecuar el servicio a los fines a partir d los cuales había sido fabricad, pero no como la mejora del producto mismo. Dicho sistema suponía incurrir en un costo adicional al implicar la retirada del producto, después de que el fallo en la cadena de producción hubiera tenido lugar y por lo tanto, impedía su comercialización. Como consecuencia se añadía un costo a un producto del que no se iba a obtener beneficio alguno

\section{Introducción a la calidad turística}

"El concepto de calidad hoy en día tiene de por sí un significado extenso y se reconoce que es aplicable a todo tipo de actividad o sector, sin exclusiones". ${ }^{3}$

Dicho esto, es incuestionable que el amplio conjunto de actividades y actores que conforman el sector 'Turismo' requiere un tratamiento muy específico, por la variedad y complejidad de las interacciones que se producen entre todo y todos aquellos que

${ }^{2}$ Calidad en el servicio y satisfacción al Cliente- Dra. Cristina Iglesias (Universidad de Quilmes)pag. 17-21

${ }^{3}$ Roberto Boullon Calidad Turística-en la pequeña y mediana empresa- Bs. As 2033. pag.63-65 
conforman 'la oferta' y los destinatarios de dicha oferta, los clientes, o más adecuadamente, los turistas.

Pensemos que un turista no sólo interactúa con las organizaciones directamente prestatarias de los servicios específicos (alojamiento, restauración, etc.); su percepción y, por tanto, su grado de satisfacción, dependerá también y sensiblemente del entorno y contexto en que se realiza dicha prestación de servicio, tanto es sus características 'físicas' como en sus características 'humanas' y organizativas o funcionales. ${ }^{4}$

Por tanto, y dicho brevemente, "los enfoques actuales de Calidad aplicados al Turismo tienen en cuenta la necesidad de actuar sobre el contexto, lo que se plasma en los Planes dirigidos a los 'Destinos', sean éstos definidos geográfica, cultural, deportivamente o por un vinculo o hilo conductor (por ejemplo, las 'Rutas')"

También es preciso actuar sobre el factor humano que se relaciona con el turista, lo que nos incluye prácticamente a todos, de ahí la necesidad de sensibilizar y concienciar al conjunto de ciudadanos.

Finalmente, y en el centro de la escena, están las organizaciones públicas o privadas que son actores preferentes en la prestación de servicios al turista, organizaciones para las que se han desarrollado diversos enfoques, pautas de actuación o sistemáticas, dirigidas todas ellas a asegurar que la prestación de dicho servicio se realiza en condiciones adecuadas para:

Cumplir con los compromisos explícitos e implícitos contraídos con el turista.

Hacerlo en condiciones que logren el mayor grado de satisfacción de dicho turista con el servicio recibido.

Hoy en día, y afortunadamente, existe un grado significativo de avance en la definición, formalización y gestión de dichas sistemáticas, puesto a disposición de las organizaciones en forma de Modelos de Referencia, y también en paralelo se han desarrollado esquemas

\footnotetext{
${ }^{4}$ Gestión de la Calidad de los Procesos Turísticos Mar Alonso Almeida Lucia Barcos Rendi, Juan Ingacio Martín Castilla - Ed Sintesis.-

${ }^{5}$ Roberto Boullon en su obra Calidad Turística era Edición Buenos Aires en la pequeña y mediana empresa . 1nos habla que para saber en qué consiste la palabra calidad.
} 
de validación y reconocimiento público del grado en que las organizaciones han adoptado (con éxito) dichos Modelos, de modo que: el mundo exterior y, más precisamente, los turistas, tengan una visión y confianza mayores en la capacidad de una organización para prestarle el servicio que espera.

La organización esté en condiciones para prestar, continuadamente, dicho servicio de manera satisfactoria.

La forma más común que adoptan dichos reconocimientos es 'Certificado', 'Sello', 'Bandera' o 'Marca'.

\section{Antecedentes de la normativa hotelera vigente}

En la década del 70 la Ley Nacional y su Decreto Reglamentario, Santa Fe, La Pampa, San Juan. En la década del 80 Catamarca, Chaco, Ciudad de Buenos aires, Córdoba (2000), Entre Ríos, Formosa Jujuy , Misiones , Salta , Santiago del Estero, Tucumán

Década del 90, Tierra del Fuego (2001).

Década presente Provincia de Buenos Aires (2007) Rio Negro (2003) San Luis (2005) y Mendoza (2007)

Podemos situar como punto de partida para referenciar el marco normativo de los alojamientos turísticos en Argentina la sanción de la Ley 17752 en el año 1968, que estableció un régimen de promoción que permitió por medio de deducción de montos imponibles, exenciones impositivas y beneficios a los inversores para la construcción de "hoteles de turismo internacional".

En Argentina las leyes que rigen la actividad son tres:

Ley 17.752

Esta ley es del año 1968 y detalla los requisitos edilicios para que un hotel sea considerado "Hotel de Turismo Internacional".

\section{Ley $18.828{ }^{6}$}

En el artículo número 1, que se transcribe a continuación, quedan expresamente detallados los establecimientos sujetos a esta ley, de la siguiente manera:

"Los establecimientos comerciales en zonas turísticas o comprendidos en planes nacionales de promoción del turismo y los que por sus características el organismo de

\footnotetext{
${ }^{6}$ Ley 18.828 Ley Nacional de Hotelería.-
} 
aplicación declare de interés para el turista, que ofrezcan normalmente hospedaje o alojamiento en habitaciones amuebladas por períodos no menores al de una pernoctación, a perssonas que no constituyan su domicilio permanente en ellos, quedan sujetos a la presente Ley y a las normas que se dicten en su consecuencia, sin perjuicio de las reglamentaciones locales en cuanto no se les opongan." 7

Entre otros requisitos que exige esta ley, se destacan ciertas obligaciones, como la inscripción en el Registro Hotelero Nacional, y la consignación de la denominación, clase, categoría y número de inscripción en toda la documentación o publicidad que cada establecimiento utilice.

Los decretos son dos: Decreto 2.253/70: establece como organismo de aplicación de la ley 18.828 a la Dirección de Turismo y le confiere la responsabilidad del Registro Hotelero Nacional. Fija también, a través de varios artículos, los requisitos necesarios para que los hoteles alcancen determinadas categorías, definidas, en forma algo curiosa, según "soles". La categoría máxima posible, siguiendo esta calificación, era la de cuatro soles, aplicable a los hoteles que, según la ley 17.752, se consideraban "Hoteles de Turismo Internacional”. Hasta donde llega el conocimiento de la autora, quien realizó una investigación específica en la Secretaría de Turismo de la Ciudad Autónoma de Buenos Aires, esta forma de categorización no tuvo aplicación efectiva. De todas formas, el decreto 2.253/70 representa el primer intento en el país de establecer categorías de acuerdo a parámetros objetivos.

La categorización según soles fue modificada por estrellas en el decreto 1818 del año 1976, estableciendo las siguientes clases y categorías:

- Hosterías: 1,2 y 3 estrellas

- Moteles: 1, 2 y 3 estrellas

- Hoteles: 1, 2, 3, 4 y 5 estrellas. Las categorías 4 y 5 estrellas pasan a ser equivalentes a "internacional" o "de lujo" 
El mismo decreto define también los requisitos mínimos para la homologación de hoteles, hosterías y moteles, como alojamiento turístico según las distintas clases y categorías; obliga a la inscripción en el Registro Hotelero Nacional y faculta la constitución de un Consejo Hotelero Nacional con participación del sector privado. (Schlüter, 2003).

Decreto 7.951/72: este decreto es una modificación del Decreto 3091/68 (Decreto Nacional de la Ley 17752 sobre Promoción de la Construcción de Hoteles de Turismo Internacional). Desde el punto de vista de los objetivos del presente trabajo, no reviste mayor interés. Otros documentos del marco regulado son:

- Ordenanza Municipal de la Ciudad de Buenos Aires, 36.136, de octubre de 1980, sobre alojamientos turísticos (detallada más adelante porque concierne a los hoteles de la ciudad de Buenos Aires y se relaciona directamente con los propósitos de este trabajo)

\section{Resolución 311/99 ${ }^{8}$}

Reglamento internacional de hoteles

Convenio hotelero entre la Asociación Internacional de Hotelería y la Federación Universal de Asociaciones de Agentes de Viajes, sobre los contratos entre Agencias de viajes y hoteles.

Ordenanza Municipal de la Ciudad de Buenos Aires sobre alojamientos turísticos Número 36.136 ${ }^{9}$. Esta ordenanza fue sancionada en octubre de 1980. Tiene su base en la Ley 18.828, y define el régimen de clasificación de los alojamientos turísticos de la Ciudad de Buenos Aires mediante la creación del Registro de Alojamientos Turísticos, determinado así su clasificación y categorización. Al mismo tiempo, contempla los aspectos referidos a la registración, la fiscalización y la supervisión de los mismos, y enumera los requisitos para su cumplimiento, según sean la clase y la categoría del establecimiento.

Alojamiento Turístico, de acuerdo a esta Ordenanza, es aquel establecimiento en el cual se presta al turista el servicio de alojamiento mediante contrato, por un período no inferior a una pernoctación, pudiendo ofrecer otros servicios complementarios. Se consideran como tales:

\footnotetext{
${ }^{8}$ Ley 18.828 y Resolución 311/99

${ }^{9}$ Ordenanza Municipal de la Ciudad de Buenos Aires sobre alojamientos turísticos no 36.136
} 
1. Los Hoteles (comprendidos en las especificaciones de la Ley 18.828): hotel es aquel alojamiento que puede prestar al turista, mediante contrato de hospedaje, el servicio de alojamiento, comidas, desayuno, bar, recepción, portería y personal de servicio, sin perjuicio de los demás que para cada categoría expresamente se indiquen, y con una capacidad mínima de 10 habitaciones con 20 plazas.

Los Appart-Hotel o Appart-Residencial ${ }^{10}$

Los Hospedajes Turísticos

Los Campamentos de Turismo

Los Alojamientos Turísticos se clasifican con relación a su:

a) Clase: en Hoteles, Appart-Hotel, Campamentos y Hospedajes.

b) Categorías:

1) Hoteles: 5-4-3-2-1 estrellas;

2) Appart Hotel: 3-2-1 estrellas;

3) Campamentos: $1^{\mathrm{a}}$ y $2^{\mathrm{a}}$;

4) Hospedajes: A y B.

Son requisitos mínimos para que un establecimiento pueda ser clasificado en la categoría de Hotel Turístico, las siguientes condiciones:

a) Ocupar la totalidad de un edificio o parte del mismo completamente independiente constituyendo sus dependencias un todo homogéneo, con entradas, ascensores y escaleras de uso exclusivo.

b) Contar con entrada de pasajeros independiente a la de servicio.

c) Tener servicio telefónico público, con cabina acústicamente aislada ubicada preferentemente en el local destinado a recepción y portería.

d) Cuando existan en el establecimiento salones de convenciones, usos múltiples o reuniones sociales deberán estar aisladas acústicamente y los mismos deberán contar con acceso a un vestíbulo de recepción, con guardarropa instalaciones sanitarias independientes para cada sexo, y por lo menos una cabina telefónica acústicamente aislada.

${ }^{10}$ Ley 18.828 Ley Nacional de Hotelería vigente 
e) Los ascensores deberán tener una capacidad mínima de 4 pasajeros y deberán estar habilitados por la autoridad respectiva.

f) Las habitaciones estarán individualizadas en la parte anterior de la puerta, con un número cuyas primeras cifras correspondan al número del piso.

g) Deberá contar con un recinto destinado a vestuarios y servicios sanitarios para el personal diferenciados por sexo.

h) Todos los establecimientos deberán tener las tarifas en las habitaciones. ${ }^{11}$

i) Todas las habitaciones estarán equipadas al menos con los siguientes muebles e instalaciones:

1) Camas individuales cuyas dimensiones mínimas serán de $0.80 \times 1.85 \mathrm{~m}$. Dobles cuyas dimensiones serán de 1.40 x 1.85 m.;

2) Una mesa de noche o mesada con superficie mínima de $0.15 \mathrm{~m}$ por plaza;

3) Un sillón, butaca o silla por plaza y una mesita escritorio;

4) Un portamaletas;

5) Un armario de no menos de $0.55 \mathrm{~m}$ de profundidad y $0.90 \mathrm{~m}$ de ancho con un mínimo de 4 cajones;

6) Una alfombra de pie de cama, las medidas mínimas serán de 1.20 x $0.50 \mathrm{~m}$ por cada plaza, excepto cuando la habitación esté totalmente alfombrada;

7) Una lámpara o aplique de cabecera por cada plaza;

8) Junto a la cabecera de cada cama, un pulsador de llamada al personal de servicio con señal luminosa o acústica salvo que esté previsto para tal fin el uso del teléfono;

9) El suministro de agua será como mínimo de 200 litros por persona y por día;

j) Cada habitación deberá contar como mínimo por día y por plaza con un juego de 2 toallas de mano y un toallón de baño, papel higiénico y jabón;

k) Deberá contar con ropa de cama adecuada, debiéndose cambiar como mínimo 2 veces a la semana, como así también cuando haya cambiado el pasajero;

A continuación se puntualizarán los requisitos mínimos para que un establecimiento sea clasificado bajo las clases 4 y 5 estrellas, ya que las demás no son motivo de estudio en el presente trabajo.

${ }^{11}$ Ley 18.828 Ley Nacional de Hotelería 
Hotel 4 estrellas: Son requisitos mínimos para que un hotel sea registrado en categoría 4 estrella, además de los indicados en el Artículo $9^{\circ}$, los siguientes:

Tener una capacidad mínima de 100 plazas en 50 habitaciones.

Todas las habitaciones deberán tener baño privado.

3. Tener un número de "suites" equivalentes al $5 \%$ del total de las habitaciones. Cada "suite" deberá tener como mínimo: dormitorio, sala de estar y baño y cada uno de ellos, las medidas mínimas que se establecen para las habitaciones dobles en los incisos siguientes.

4. Las superficies mínimas de las habitaciones serán las siguientes:
a. Habitación simple: $12 \mathrm{~m}^{2}$
b. Habitación doble: $14 \mathrm{~m}^{2}$
c. Habitación triple: $17 \mathrm{~m}$
d. El lado mínimo no será inferior a: 2,50 m
e. Altura mínima: 2,60 m
f. Cubaje mínimo: $15,00 \mathrm{~m}$

Cuando una habitación posea altura superior que $3 \mathrm{~m}$ se considerará esta dimensión como la máxima para determinar su cubaje.

5. Las habitaciones triples no deberán exceder del $10 \%$ del total. La superficie mínima de los baños privados será de $3,20 \mathrm{~m}^{2}$ con un lado mínimo de 1,50 m. Los baños privados de las habitaciones y suites estarán equipados con: lavabo, bidet, bañera con ducha, (estos artefactos serán independientes y contarán con servicio permanente de agua fría y caliente mezclables), inodoro, botiquín iluminado, toallero y tomacorriente. Tener locales destinados a recepción y portería con una superficie mínima de $40 \mathrm{~m}^{2}$ en conjunto, más de $0,20 \mathrm{~m}^{2}$ por plaza a partir de las 80 plazas. Tener sala de estar con una superficie mínima de $50 \mathrm{~m}^{2}$ más de $0,20 \mathrm{~m}^{2}$ por plaza a partir de las 80 plazas. Dicha sala tendrá comunicación directa con la recepción y contará con servicios sanitarios para público, independientes para 
cada sexo. Tener salón comedor-desayunador, cuya superficie mínima sea de 50 2 m más $1 \mathrm{~m}$ por cada tres plazas a partir de las 100 plazas. Esta proporción será de $0,60 \mathrm{~m}^{2}$ por cada tres plazas cuando no se preste el servicio de comida.

Tener salón comedor para niño, cuando sea prestado el servicio de comida. Tener salones de uso múltiple cuya superficie no sea inferior $0,50 \mathrm{~m}^{2}$ por plaza. Tener un office por planta, dotado de: teléfono interno, mesada con pileta, armario para artículo de limpieza, montaplatos, si el edificio tuviere más de una planta y servicios sanitarios para el personal. Tener alfombrado total en todas las habitaciones y salones. Podrá prescindirse de este requisito cuando el solado sea de primera calidad. En caso de tener el edificio más de dos plantas contará con un mínimo de un ascensor por cada 100 plazas o fracción, descontadas las correspondientes a planta baja, pudiendo suplir la cantidad de ascensores con una mayor capacidad de los mismos, dotándolos además de la maniobra selectivacolectiva. Deberá también contar con un ascensor de servicio independiente. Tener espacio para estacionamiento cuyo número de cocheras sea igual o mayor al $20 \%$ del total de las habitaciones y podrá estar integrado al edificio o ubicado en sus adyacencias, hasta $150 \mathrm{~m}$ medidos en línea recta o quebrada sobre el cordón de la acera, a partir del eje central de la puerta principal de acceso al estacionamiento. Contará con servicios de vigilancia y de transporte de vehículo, desde el hotel a la cochera y viceversa, durante las 24 horas. Tener calefacción en todos los ambientes incluidos los baños, por sistemas centrales o descentralizados por planta o grupo de habitaciones.

18. Tener refrigeración en todos los ambientes por sistemas centrales o descentralizados.

19. Todas las habitaciones estarán equipadas con radio, música ambiental, televisión, y de servicio telefónico interno que además permita la comunicación con el exterior a través de un conmutador.

20. Tener servicio de télex. 
21. Ofrecer al público, además del servicio de alojamiento, los de desayuno, refrigerio, bar diurno y nocturno y servicio en las habitaciones ${ }^{12}$.

22. Contar con servicio de lavandería, la que deberá estar integrada al establecimiento.

23. Tener cofres de seguridad individuales a disposición de los huéspedes, pudiendo aquellos estar ubicados en las habitaciones o en las dependencias administrativas del establecimiento ${ }^{13}$.

24. Tener personal bilingüe para la atención de la recepción y el salón comedor, debiendo como mínimo, en cada turno de trabajo, encontrarse personal que hable inglés y otro idioma extranjero.

Hotel 5 estrellas: Esta categoría equivale a la denominación "internacional" o de "lujo" mencionada en el Artículo 6º inciso a) de la Ley 18.828, además de los indicados en el Artículo $9^{\circ}$, los siguientes:

Tener una capacidad mínima de 200 plazas en 100 habitaciones.

Todas las habitaciones deberán tener baño privado.

El 80\% de las habitaciones deberá tener vista al exterior.

4. Tener un número de suites equivalentes al $7 \%$ del total de las habitaciones. Cada suite deberá tener como mínimo: dormitorio, sala de estar y baño y cada uno de ellos las medidas mínimas que se establecen para las habitaciones dobles en los incisos siguientes.

5. Las superficies mínimas de las habitaciones serán las siguientes:
a. Habitación simple: $14 \mathrm{~m}^{2}$
b. Habitación doble: $16 \mathrm{~m}^{2}$.
c. El lado mínimo no será inferior a 2,50 m.

La superficie mínima de los baños privados será de $3,20 \mathrm{~m}^{2}$ con un lado mínimo de 1,50 $\mathrm{m}$.

${ }^{12}$ Ley 18.828
${ }^{13}$ Ley 18.828 
Los baños privados de las habitaciones y suites estarán equipadas con: Lavabo, bañera con ducha, bidet (estos artefactos serán independientes y contarán con servicio permanente de agua fría y caliente mezclable), inodoro, botiquín iluminado, toallero, tomacorriente y extensión telefónica.

Tener locales destinados a recepción y portería con una superficie mínima de 50 $\mathrm{m}^{2}$ en conjunto, más $0,20 \mathrm{~m}^{2}$ por plaza a partir de las 120 plazas.

Tener sala de estar con una superficie mínima de $60 \mathrm{~m}^{2}$, más $0,20 \mathrm{~m}^{2}$ por plaza a partir de las 100 plazas. Dicha sala tendrá comunicación directa con la recepción y contará con servicios sanitarios para el público, independientes para cada sexo.

10. Tener salón comedor-desayunador cuya superficie mínima sea de $100 \mathrm{~m}^{2}$, más 1 metro cuadrado por cada 3 plazas a partir de las 200 plazas.

11. Tener salón comedor afiliar para comidas ligeras, niños y acompañantes.

12. Tener salones de uso múltiple cuya superficie no sea inferior a $0,50 \mathrm{~m}^{2}$ por plaza.

13. Tener salón de convenciones con una superficie de $1,50 \mathrm{~m} 2$ por plaza. Dicho salón deberá contar con las siguientes instalaciones complementarias, salas y ambientes para secretaría, instalaciones para traducción simultánea, y para equipos de reproducción de documentos, salas de reuniones de comisiones, sala para periodistas e instalaciones para proyecciones cinematográficas.

14. Tener un office por planta, dotado de: Teléfono interno, mesada con pileta, armario para artículos de limpieza, montaplatos, si el edificio tuviere más de una planta, servicios sanitarios para el personal.

15. Tener alfombrado total en todas las habitaciones y salones. Podrá prescindirse de este requisito cuando el solado sea de primera calidad.

16. En caso de tener el edificio más de dos plantas contará con un mínimo de un ascensor por cada 100 plazas o fracción, descontadas las correspondientes a planta baja, pudiendo suplir la cantidad de ascensores con una mayor capacidad de los mismos, dotándolos además de maniobra selectiva-colectiva. Deberá también contar con un ascensor de servicio independiente. 
17. Tener espacio para estacionamiento cuyo número de cocheras sea igual o mayor al $20 \%$ del total de las habitaciones y podrá estar integrado al edificio ubicado en sus adyacencias, hasta $150 \mathrm{~m}$ medidos en línea recta o quebrada sobre el cordón de la acera, a partir del eje central de la puerta principal de acceso al establecimiento. Contará con servicio de vigilancia y de transporte del vehículo desde el hotel a la cochera y viceversa, durante las 24 horas.

18. Las dependencias de servicio serán independientes de las instalaciones destinadas al uso de pasajeros y visitantes.

19. Tener pileta de natación cuya superficie sea proporcional al número de habitaciones del hotel, a razón de $0,50 \mathrm{~m}^{2}$ por plaza a partir de un mínimo de 100 $\mathrm{m}^{2} \mathrm{y}$ hasta un máximo de $300 \mathrm{~m}^{2}$ con una profundidad promedio de $1,20 \mathrm{~m}$ en toda su extensión.

20. Tener calefacción en todos los ambientes, incluidos los baños, por sistema central o descentralizado, por planta o grupo de habitaciones.

21. Tener refrigeración en todos los ambientes por sistemas centrales o descentralizados.

22. Todas las habitaciones estarán equipadas con radio, música ambiental y televisión y servicio telefónico interno, que además permita la comunicación con el exterior a través de un conmutador.

23. Tener un servicio de télex.

24. Ofrecer al público, además del servicio de alojamiento, los de comida, desayuno, refrigerio, bar diurno y nocturno y servicio en las habitaciones.

25. Contar con servicio de lavandería, la que deberá estar integrada al establecimiento.

26. Tener cofre de seguridad individual a disposición de los huéspedes, pudiendo aquel estar ubicado en las habitaciones o en las dependencias administrativas del establecimiento.

27. Tener personal bilingüe para la atención de la recepción y el alón comedor, debiendo como mínimo en cada turno de trabajo, encontrarse personal que habla inglés y otro idioma extranjero. 
Resulta pertinente observar que algunos de los requerimientos han quedado desactualizados, como el que refiere el ítem 23 (la numeración original de la ordenanza ha sido cambiada, por razones de mejor visualización). Nadie esperaría, en el presente, que un hotel contara con servicio de télex $\mathrm{y}$, en cambio, consideraría indispensables facilidades tales como el fax o la conexión a Internet. En lo que se refiere a las dimensiones de la pileta de natación (ítem 19) las exigencias son anacrónicas, puesto que los grandes hoteles deberían poseer piletas más grandes que las que existen en muchos clubes deportivos. En la práctica, este requisito no se cumple.

Hay que tener en cuenta que, según procedencia y origen de los huéspedes, cumplir con los requisitos que exige la ley no significa que se esté brindando un servicio de calidad.

Por ejemplo, para turistas de Estados Unidos o Canadá que un baño cuente con bidet es totalmente irrelevante.

Tanto el marco de la ley 18.828 como el de la ordenanza municipal, resultan incompletos, pues fueron calificados en cuanto a equipamiento e instalaciones. Convenio Colectivo de trabajo

Otro elemento importante del marco regulado es el CONVENIO COLECTIVO DE TRABAJO N ${ }^{\circ} 125 / 90^{14}$, destinado a regular la prestación de servicios propios de la actividad hotelera y gastronómica; desarrollado por la Unión de Trabajadores Gastronómicos de la República Argentina (UTGRA) y la Federación Empresarial Hotelera Gastronómica de la República Argentina (FEHGRA) quienes son los encargados de representar los intereses de los trabajadores.

Uno de los capítulos de este convenio establece las categorías y las funciones de los empleados, describiendo las tareas que se adecuan a la Ley de Contrato de Trabajo y a aquellos comportamientos (por parte del empleador y del trabajador)

${ }^{14}$ Administración hotelera María Teresa de las Casas Ed. Siglo 21 Bs As 
que sean una consecuencia del mismo, dirigidos a prestar el buen servicio. La cantidad de puestos va a depender directamente de la categoría y el tamaño del hotel.

A continuación se enuncian las categorías y funciones:

JEFE DE RECEPCIÓN: ${ }^{15}$ Es de su responsabilidad dirigir a todo el personal de recepción y portería, tomar reservas de habitaciones, llevar el control de habitaciones vacías y en uso, recibir a los huéspedes y asignarles alojamiento, mantener informado a otros sectores del establecimiento sobre el movimiento de huéspedes. Efectuar la facturación.

RECEPCIONISTA: Es de su responsabilidad tomar reservas de habitaciones, llevar el control de habitaciones vacías y en uso, recibir a los huéspedes y asignarles alojamiento, mantener informado a otros sectores del establecimiento sobre el movimiento de huéspedes. Efectuar la facturación. Actuar bajo la supervisión del jefe de recepción o del principal, realizando las tareas conforme a lo detallado para el sector.

CONSERJE: Colabora con el recepcionista y lo sustituye cuando es necesario. Es encargado de la correspondencia, pequeñas encomiendas y encargos especiales de los pasajeros. Proporciona a éstos, cada vez que le es solicitada información de cualquier índole. Dirige al personal de portería.

PORTERO: Es el encargado de la puerta del establecimiento, siendo su obligación colaborar en forma directa con los recepcionistas y/o conserjes.

AUXILIARES DE PORTERIA: Es todo aquel personal que depende del jefe de recepción, recepcionistas, conserje, o portero. Dicho personal debe cumplir cualquiera de las tareas asignadas que corresponden al sector. Pertenecen a esta categoría los siguientes:

BAGAJISTA: Es el encargado del transporte de todos los bultos de los pasajeros. ASCENSORISTAS: Es el encargado de manejar los ascensores.

MENSAJERO: Es el encargado de llevar todos los mensajes del establecimiento y de los pasajeros.

\footnotetext{
${ }^{15}$ Administacion Hotelera Maria de las Casas Ed. Siglo 21 Bs As.-
} 
GARAJISTA: Es el encargado de estacionar los coches en la playa de estacionamiento.

CADETE Y/O CADETE DE PORTERIA: Colabora en portería con todo el personal de la misma.

GUARDARROPISTA: Es el encargado del guardarropas.

JEFE DE TELEFONISTA: Es el encargado del sector en aquellos establecimientos que lo estimen necesario para un mejor servicio. Depende del jefe de recepción.

TELEFONISTA: Opera lo conmutadores telefónicos fax, para servir necesidades de los clientes y del establecimiento.

GOBERNANTA PRINCIPAL: Tiene la responsabilidad sobre la limpieza y buen estado de presentación de las habitaciones, veredas y accesos del hotel, vestíbulo y zona de circulación, salones, oficinas administrativas. Atiende todos los pedidos de artefactos, ropa blanca. Hacer cumplir y vigilar el trabajo de todo el personal a su cargo.

MUCAMA: Es la responsable de la limpieza, servicio y atención de las habitaciones y/o departamentos como así también del sector a su cargo.

VALET: Es el encargado de la atención directa de los pasajeros desde su llegada hasta su egreso y a pedido de éstos desarmará y armará valijas, mantendrá la ropa limpia y planchada así como lustrado el calzado y el orden de los armarios de la habitación.

CAPATAZ DE PEONES: Tiene por misión mantener la limpieza de Todos los sectores públicos del establecimiento. PEON GENERAL (O PEON DE LIMPIEZA); Realiza todas las tareas generales de limpieza y todos los movimientos de muebles, artefactos y bultos. PEON DE PISO: Es el que se encarga de colaborar con la mucama en el traslado de colchones, etc.; y de la limpieza a fondo de los pasillos y escaleras. JEFE DE LENCERIA Y/O LAVADERO: Lleva el control de toda la ropa y la distribución de tareas del personal de la lencería. Tiene como subordinado: CON CATEGORIA DE OFICIAL: Oficial modista o planchadora. 
CON CATEGORIA DE MEDIO OFICIAL: Planchadora a planchón, lavandera a mano, costurera, marcadora, lavador mecánico, centrifugador, planchadora en calandra y dobladora.

CON CATEGORIA DE PEON: Repartidora.

MAITRE PRINCIPAL: Es el responsable de coordinar con los restantes maîtres la distribución de las tareas. Es el jefe de salón, encargado de distribuir los comensales en las distintas zonas del salón comedor para su mejor atención.

MAITRE: Actúa bajo la supervisión del maître principal, donde lo hubiere. Es el responsable de supervisar al personal de mozos y comises y verificar el cumplimiento de las comandas por la cocina.

CHEF DE FILA: Colabora con el maître en la distribución de las plazas, siendo su eventual reemplazante.

MOZO: Se encarga de la "Mise en Place" o de su lugar de trabajo, donde atiende al público en el servicio de comedores y bebidas.

COMIS: Es el auxiliar del mozo, debe retirar las comidas de la cocina y asistir al mozo para servirlas, trasladar el carro, de fiambres o de postres, a donde le indique el mozo, manteniendo tanto el carro como el aparador en condiciones con sus diferentes elementos.

COMIS DEBARRASSEUR: Es el aprendiz de comis, recogiendo el servicio limpio y manteniendo el aprovisionamiento del aparador.

BARMAN: Es el empleado que prepara cocteles y sirve bebidas en la barra.

JEFE DE BRIGADA: Es el responsable del funcionamiento de la cocina y tiene a su cargo la confección del menú, debiendo realizar los pedidos de mercaderías.

JEFE DE PARTIDA O COCINERO: Es el encargado de las distintas especialidades gastronómicas.

SAUCIER: Es el encargado de todas las salsas, menos de pescados y de las minutas, siendo también Segundo Jefe de cocina.

ENTREMETIER: Es el encargado de la elaboración de distintas sopas cremas, de los platos preparados a base de huevos, tales como omelettes y tortillas.

POISSONIER: Es el encargado de la elaboración de los platos preparados a base de pescados y mariscos con sus salsas correspondientes. 
PATISSIER: Es el encargado de las comidas a base de pastas.

GARDER MANGER: Es el encargado de despostar y cortar la carne.

ROTTISSOIRE: Es el parrillero, quien tiene a su cargo los embutidos, achuras, carnes y pollos, etc., que salen del grill.

FIAMBRERO: Es el encargado de la elaboración de todos los platos fríos incluido el Buffet Froid.

PASTELERO: Es el encargado de la elaboración y despacho de todo lo referido a la pastelería y demás postres.

LE ABOUYEUR: Es el encargado en la cocina de recibir las comandas que entran y las canta a su respectiva partida, entrega los pedidos y pone en conocimiento del personal del salón las comidas que se han agotado.

COMIS DE COCINA: Es el auxiliar del jefe de partida.

AYUDANTE DE COCINA: Colabora con el jefe de partida y el comis, en la preparación, no en la cocción.

PEON DE COCINA: Se encarga de la limpieza de mercaderías, mesadas, cocina, piletas, ollas y otros utensilios de la sección.

JEFE DE OPERARIOS DE SERVICIOS VARIOS Y/O MANTENIMIENTO: Supervisa la sala de máquinas, talleres de mantenimiento y oficios varios, la conservación del edificio, mantenimiento de equipos y elementos contra incendio $\mathrm{y}$ al personal asignado a esas tareas.

OFICIAL DE OFICIOS VARIOS: Un oficial podrá cubrir más de una especialidad, de acuerdo a las necesidades del establecimiento.

PERSONAL DE VIGILANCIA: Se encarga de la seguridad del establecimiento, de los empleados, los clientes y de sus pertenencias.

BAÑERO: Es el trabajador responsable del control y custodia del natatorio, conforme a las modalidades propias de dicha actividad.

EMPLEADO PRINCIPAL: Es el responsable de cumplir y/o hacer cumplir funciones determinadas bajo su responsabilidad (cuentas corrientes, costos y control, compras, tesorería, ventas, control, depósito gambuzas, cajeros principales, personal, procesamiento de datos, y actividades similares). 
Dos años después de la ley 18828 crearía un sistema vigente que integra tanto al establecimiento surgidos de planes nacionales de promoción como a los que ofrecieran "hospedaje o alojamiento en habitaciones amuebladas por periodos no menores al de una pernoctación, a personas que no constituyan su domicilio permanente en ellos". La ley no regula la oferta de servicios de alojamiento, ni su clasificación. Tal solo crea el Registro Hotelero Nacional que servirá de base, a una futura clasificación del Establecimiento. Los requisitos para la clasificación fueron derivados al decreto reglamentario. La ley impone las siguientes obligaciones

-Inscribirse en el registro hotelero nacional

-Consignar en forma precisa y explicita la denominación, clase, categoría y número de inscripción en el Registro Hotelero Nacional, en publicidad, correspondencia, facturas y toda otra documentación o material de propaganda que utilicen.-

- Comunicar dentro de los 30 días de producida, cualquier alteración o modificación de sus características o servicios"

Reservándose la posibilidad de delegar en las autoridades locales las facultades sancionatorias para quienes incumplieran con estos requisitos. Por lo tanto solo aquellos establecimientos inscriptos podían solicitar la calificación de "alojamiento turístico" lo que les permitía acceder a franquicias impositivas, créditos, etc.

Es importante aclarar que el Registro Hotelero Nacional no es de utilidad para conocer la totalidad de la oferta hotelera del país y su clasificación, sino únicamente aquellos establecimientos ubicados en zonas turísticas o comprendidas en planes nacionales de promoción del turismo o los que, por sus características, el órgano de aplicación declare de interés para el turista.

El decreto reglamentario de la Ley 18828 vigente es el 1818/76, el cual determina el órgano de aplicación ( la Secretaria de Estado de Deportes y Turismo) autorizando a constituir con carácter consultivo un Consejo Hotelero Nacional en el que tendrá participación el Sector Privado" el decreto enumera los requisitos debe reunir el establecimiento cualquiera que sea la clase y categoría y clasifica a 
los establecimientos en tres clases Hostería, Motel y hotel y los categoriza por Estrella (1 a 5 para hoteles y 1 a 3 para Hosterías moteles) Las diferencias entre las distintas clases y categorías está dada fundamentalmente por las dimensiones de las habitaciones y dependencias y por la diversidad de servicios accesorios a disposición del pasajero.

La Ley Nacional de Hotelería no se ha actualizado y por lo tanto no contempla las nuevas modalidades de alojamiento.

Este convenio tiene como objetivo respetar los intereses de los empleados, en ningún momento nombra a los clientes; sin embargo, cuando los parámetros fijados en él no son respetados por parte del empleador, los empleados demuestran una actitud de disconformidad, y esta situación lleva a la desatención y a una mala prestación del servicio, que termina perjudicando al cliente.

Las provincias han adherido a la ley nacional y su decreto reglamentario hasta la década del 80 realizando algunas modificaciones tales como incluir la modalidad del Apart Hotel, Cabañas, Residencial y otros. A partir de la década del 90 la provincia de Neuquén desarrolla un esquema normativo moderno así como en la década presente han modernizado sus leyes la provincia s de Rio Negro (2003) San Luis (2005), Buenos Aires (2007) y Mendoza (2007).

\section{Marco teórico hotelero}

El presente trabajo trata sobre la gestión de calidad en la industria hotelera. Siendo un hotel, según Dennis L. Foster $(1994)^{16}$, un establecimiento de hospedaje; hospedaje que incluye habitación, y servicio de comida y bebida en las mismas instalaciones.

\section{Concepto de alojamiento}

\footnotetext{
${ }^{16}$ Denis L. Floster. Recepción en Hotelería , Administración y operación. Mc Graw -Hill. Mexico pag.19-30,33-47,
} 
"es aquel tipo de establecimiento en el cual se presta el servicio de alojamiento mediante contrato por un periodo no inferior a una pernoctación, pudiendo ofrecer otros servicios complementarios, siempre que las personas alojados no constituyan domicilio permanente en el establecimiento o inmueble en el que se presta el servicio de alojamiento".

\section{Clasificación de alojamientos}

a. Hotel: Establecimiento que brinda servicio de alojamiento en habitaciones individuales con baño privado, departamentos y suite, con una cantidad mínima de 10 unidades de alojamiento, en el cual se preste el servicio básico de alojamiento con servicios complementarios, conforme a los requisitos que se indiquen para cada categoría.

b. Apart Hotel: Establecimiento que se agrupa unidades integradas en un solo edificio, que brinda alojamiento en unidades de alojamiento con baño privado, que cuenten con equipamiento y servicio que permite la elaboración, consumo y conservación de alimentos dentro de la unidad de alojamiento, destinado a personas que no constituyen domicilio permanente en él, y se administre en forma centralizada, pudiendo contar con servicios propios de la clase hotel. Cada unidad deberá contar como mínimo de dormitorio, baño, estar-comedor y cocina debidamente equipados. El servicio de alojamiento deberá contratarse por unidad.

c. Hostería. Establecimiento que brinda servicio de alojamiento en habitaciones individuales con baño privado, departamentos y suites, con una capacidad mínima de 5 unidades, en el cual se preste el servicio de alojamiento y otros servicios complementarios, según los requisitos indicados para cada categoría, y que por sus características no puede ser encuadrado en la clase hotel.

d. Motel. Establecimiento que brinda servicio de alojamiento en habitaciones individuales con baño privado, con acceso independiente a las habitaciones, contando con estacionamiento vehicular ubicado junto a cada unidad y en 
cantidad igual al número de unidades, en el cual se preste el servicio de alojamiento con servicios complementarios.

e. Hostal. Establecimiento que brinde el servicio de alojamiento, en habitaciones individuales con baño privado y otros servicios complementarios, localizando en edificios de valor arquitectónico, histórico -patrimonial, que a criterio del organismo de aplicación cuenten con condiciones de habitabilidad y confort adecuadas para la prestación del servicio de alojamiento.

f. Residencial. Establecimiento que brinda servicio de alojamiento en habitaciones individuales con baño privado, con una capacidad de 5 habitaciones, en el que se preste el servicio de alojamiento con o sin servicios complementarios, según los requisitos establecidos para cada categoría, y que por sus condiciones arquitectónicas y de servicios no puede ser encuadrado en las clases anteriores.

g. Albergue. Establecimiento que brinda servicio de alojamiento grupal. Dedicado al alojamiento de contingentes y/o grupos de personas, con baños comunes o privados, que cuenten con condiciones mínimas de habitabilidad fijadas por la autoridad de regulación edilicia y de servicios turísticos.

h. Apart Cabañas. Unidades de alojamiento independientes y aisladas entre sí, que formando conjunto con otras, con un mínimo de 3, brinden servicios de alojamiento, con servicios complementarios, contando como mínimo áreas de dormitorio, baño, cocina y estar comedor, debidamente equipados. Conforme lo establecido en la presente reglamentación para cada clase y categoría. El servicio de alojamiento deberá contratarse por unidad.

i. Conjunto de casas y departamentos. Unidades de alojamiento independientes, que agrupadas, y formando conjunto con otras, con un mínimo de 3 , brinden servicio de alojamiento, contando como mínimo con áreas de dormitorio, baño, cocina y estar comedor debidamente equipados.

j. Complejo turístico. Establecimiento que presta servicio de alojamiento en una o más de una clase reconocida por la presente reglamentación, sujeta en cada caso a las condiciones que rigen para cada clase, contando con servicios complementarios, y con superficies afectadas al desarrollo de actividades turísticas, deportivas, recreativas, en cantidad y diversidad de acuerdo a lo que establezca cada categoría la presente reglamentación. 
k. Complejo especializado. Establecimiento que presta servicio de alojamiento en una o más de una clase reconocida por la presente, integrado a la prestación de un servicio especializado y ajeno al alojamiento, y/o que por su localización rural se encuadre en la presente clase. En todos los casos, deberán compatibilizarse, adecuarse y ajustarse a las características del servicio de alojamiento, a los requerimientos y necesidades especiales y particulares de los servicios especializados que se prestan.

Los alojamientos pertenecientes a las distintas clases anteriores deberán reunir características de escala y de diseño, acordes con el medio urbano o rural, de localización conforme lo establezca la presente reglamentación.

\section{Tipología de unidades de alojamiento}

a. HABITACION SIMPLE: Unidad de alojamiento amoblada en forma permanente con una cama individual

b. HABITACION DOBLE: Unidad de alojamiento amoblada en forma permanente con 2 camas individuales o 1 cama de dos plazas.

c. HABITACION TRIPLE: Unidad de alojamiento amoblada en forma permanente con 3 camas individuales o 1 cama doble y 1 cama individual.

d. HABITACION CUADRUPLE: Unidad de alojamiento amoblada en forma permanente con 4 camas individuales o 1 cama doble y 2 individuales.

e. DEPARTAMENTO: Unidad de alojamiento compuesto por dos habitaciones con un hall de acceso con puerta al pasillo, atendido por un núcleo sanitario que le es propio. El ingreso al sanitario deberá ser independiente al de las habitaciones.

f. SUITE: Unidad de alojamiento compuesto por uno o más dormitorios con igual cantidad de baños y otro ambiente amoblado como sala de estar y recepción, con baño o toilette compuesto de inodoro, bidet y lavado.

g. BAÑO PRIVADO: El ambiente sanitario integrado con unidad de alojamiento individual

h. BAÑO COMUN: El ambiente sanitario que sirve a más de dos unidades de alojamiento individuales como mínimo, o a uno de características grupales. 


\section{Conceptos básicos sobre servicios hoteleros ${ }^{17}$}

a. Pensión completa. Servicio que incluye el de alojamiento brindado conjuntamente con el de desayuno, almuerzo y cena incluido en la tarifa.

b. Media pensión. Servicio que incluye el alojamiento, desayuno y una de las comidas, todo ello incluido en la tarifa.

c. Día estada. Periodo de tiempo comprendido entre 10 horas de un día y las 10 horas del día siguiente.

\section{Organización departamental del hotel ${ }^{18}$}

El siguiente esquema muestra la estructura básica de la organización de un hotel:

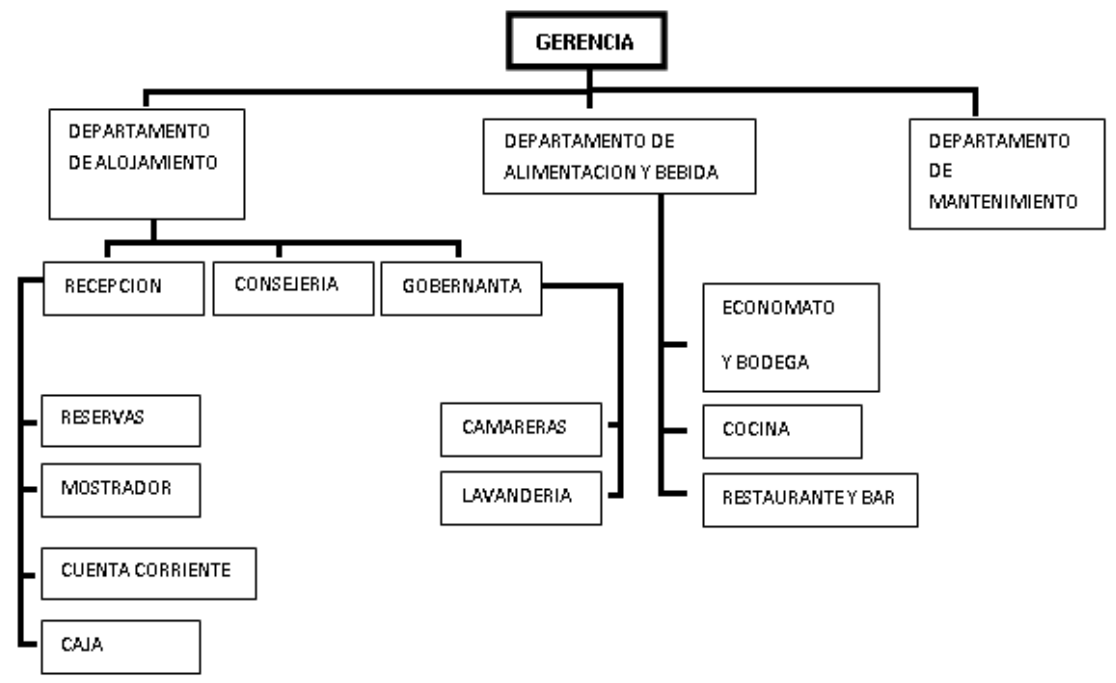

GERENCIA: Cumple el rol de planificación, fijando los objetivos generales del hotel. También determina las políticas a seguir, como pueden ser el criterio de descuentos a otorgar según la modalidad de pago.

\footnotetext{
${ }^{17}$ Administración hotelera María de las Casas. Ed. IES, Siglo 21 Bs.As. pag. 11-32 Cap. 4 pags.71-86, Capitulo 5, pags 89-105

${ }_{18}$ Administración Hotelera Maria de la Casas Ed. Siglo 21 Bs As. Ed. IES, Siglo 21 Bs.As. pag. 11-32 Cap. 4 pags.71-86, Capitulo 5, pags 89-105
} 
También tiene que organizar, o sea definir la estructura organizativa y jerárquica del hotel, definir cuáles son las funciones y responsabilidades de los recepcionistas, conserjes, mucamas, etc.

Debe gestionar, influir sobre las personas que cumplen con las diferentes funciones para que logren los objetivos planteados, motivándolos y ejerciendo un buen liderazgo. El control no escapa a las funciones que debe cumplir el gerente.

\section{El departamento de alojamiento:}

Recepción: Cuando un cliente ingresa al hotel establece contacto con la recepción, que es quien mantiene la relación más estrecha con el huésped, y cuya actividad principal es la venta de habitaciones. También cumple funciones administrativas conjuntamente con las comerciales, que se pueden desempeñar por un solo encargado, subdividirse en sub secciones, según la categoría o tamaño del establecimiento.

\section{Recepción:}

Reservas: Tiene como misión principal, la venta de la habitación; para ello debe tener una gran control sobre las reservas, para maximizar la ocupación y no vender en forma simultánea la misma habitación. Es importante destacar que una habitación no vendida hoy no se puede guardar para mañana. Por lo tanto, se pierde el producto por lo que una mala gestión en esta función significa:

- Se reserva más de lo que existe;

- Perder la venta de las habitaciones;

- No obtener la mayor beneficio de la venta.

Mostrador: Aquí es necesario que el recepcionista esté capacitado para realizar las siguientes funciones:

- Planificación de las habitaciones;

- Control de las habitaciones ocupadas, libres o bloqueadas;

- Registro de clientes, check in -check out;

- Cumplimentar la documentación (registro de pasajeros);

- Apertura de facturas;

- Estadística;

- Control de factura;

- Cierre diario de caja (cobranzas);

- Calculo de descuentos y deducciones;

- Cerrar factura (cuando el pasajero se retira). 
Cuenta Corriente: deriva el concepto del francés "main courran" y tiene a su cargo lo siguiente:

- Cargo de los conceptos consumidos por los clientes;

- Control de facturas. Supervisar el saldo;

- Cargas las liquidaciones de los departamentos de los servicios;

- Cierre diario;

- Calculo de comisiones agencias de viajes y compañías de crédito;

- Calculo de deducciones;

- Cumplimentar toda la documentación ${ }^{19}$;

- Cierre de factura;

- Calculo de cuenta de habitaciones con el mostrador.

\section{Caja:}

- Cobro de facturas;

- Cambio de moneda extranjera;

- Control de cofres de seguridad;

- Confección de liquidaciones de facturas cobradas por efectivo y crédito o cuenta corriente;

- Liquidación de cajas y divisas;

- Cumplimentar con documentación del departamento;

- Autorización de salida de equipaje.

Conserjería: Este departamento se encuentra fusionado con la recepción, salvo que la reglamentación de cada categorización de hotel establezca lo contrario.-

Este departamento es el que mantiene una relación más directa con el huésped, ya que sus funciones más relevantes son de atención directa a este, cuando el pasajero ya está alojado.

Funciones:

- Control de viajero;

- Asistencia en la llegada y salida del pasajero;

- Control y entrega de equipaje;

\footnotetext{
${ }^{19}$ Administración Hotelera Maria de las Casas Ed. Siglo 21 Bs As.- Ed. IES, Siglo 21 Bs.As. pag. 11-32 Cap. 4 pags.71-86, Capitulo 5, pags 89-105
} 
- Información interna del hotel y general;

- Correspondencia de clientes;

- Teléfono;

- Mensajes;

- Despertador;

- Vigilancia de noche;

- Encargos a efectuar fuera o dentro del establecimiento.

Botón o cadete:

- Abrir la puerta del auto del cliente;

- Carga de equipaje;

- Estacionamiento de auto;

- Guiar al huésped hasta la habitación.

\section{MOSTRADOR Y CONSEJERIA}

\section{Primer turno (mañana)}

Control de salidas

Despedida del huésped

Salida de equipaje

Planificación de ocupación de día

Seguimiento de disponibilidad de habitación con la gobernanta

Ampliación de estancias

Llegadas tempranas

Información a los demás departamentos de la llegada de clientes

$\underline{\text { Turno tarde: }}$

Asignación de habitaciones

Recibimiento del cliente

Registro de llegadas 
Control de ocupación del día

Turno noche:

Últimas llegadas (late check-in)

Primeras salidas

Control de clientes hospedados

Cierre del día

Dar parte a la gobernanta para el día siguiente

Relación de desayunos contratados.

PISOS:

Cuando un pasajero se aloja genera una serie de actividades que se relacionan con su estadía en el hotel. Una de las actividades claves es aquella que se encarga del mantenimiento, orden y limpieza del producto básico: la habitación

A la responsable de este departamento se la denomina jefe de mucamas o gobernanta, quien es la responsable de la dirección, control y seguimiento de las tareas que componen el servicio de pisos, espacios comunes, áreas internas, lavandería y lencería; así mismo es la encargada de organizar el personal a su cargo, turnos, reemplazos, etc.; siempre bajo las directrices que marque la gerencia del hotel.

Funciones básica:

- Limpieza y mantenimiento de unidades de alojamiento;

- Conservación de mobiliarios y enseres;

- Limpieza de áreas comunes;

- Revisión de habitación (control entrada-salida);

- Control de inventario de mobiliarios y enseres;

- Cambio de ropa;

- Atención al cliente.

Responsabilidades de la gobernanta:

- Organizar las tareas. Por ello se tiene que mantener contacto permanente con la recepción para establecer prioridades sobre las habitaciones que se desocupan, las que se debe hacer limpieza general, reponer los amenities, o realizar un mantenimiento; 
- Turnos de trabajo. debe cubrirse con las necesidades acorde a las fluctuaciones de ocupación pero sin dejar de contemplar la reglamentación laboral, respetando los días de franco, vacaciones o licencias;

- Revisión de los trabajos y control de las habitaciones. Es fundamental que el área pueda informar sobre los desperfectos que se puedan producir, además, se debe tener un buen control sobre el inventario de los efectos de cada habitación y los objetos personas que muchas veces los huéspedes dejan olvidados.

Sub funciones de lencería y lavandería:

- Control e inventario de todas la ropa del hotel;

- Lavado y planchado de la ropa del hotel;

- Atención al servicio de vestuario de clientes.

Sub funciones de camareras:

- Limpieza de habitaciones;

- Cambio de ropa (amenities, reposición de frigo bar y cambio de toallas);

- Cobertura (mantenimiento de las habitaciones (abrir cama).

\section{DEPARTAMENTO DE ALIMENTACION Y BEBIDA:}

A este departamento habitualmente se lo denomina habitualmente de alimentación y bebidas, y se puede subdividir, según su importancia y tamaño en:

Economato y bodega: es el departamento que se encargado de la reposición, almacenamiento, conservación y control de toda clase de productos que pasaran a formar parte del stock, y, según las necesidades, se distribuyen en los restantes departamentos. Funciones:

- Mantener la relación con los proveedores;

- Comprobar las existencias de mercaderías y realizar los pedidos;

- Cotejar los precios del mercado;

- Efectuar las compras;

- Controlar la calidad de los productos;

- Recepción y almacenamiento;

- Distribución de los pedidos a los departamentos del hotel;

- Control de stock de mercaderías.

Cocina: si bien el restaurante es el que ofrece el servicio al cliente, si la cocina la que debe cuidar la calidad del proceso y el producto final que sale de ese proceso. 
Funciones:

- Previsión diario de la demanda teniendo en cuenta las reservas para eventos, nivel de ocupación, etc.;

- Pedido de suministros al departamento de economato;

- Preparación del servicio;

- Recepción de comanda;

- Elaboración de lo comandado;

- Control de consumo;

- Control de existencia para el servicio siguiente.

La organización de este departamento varía según le tipo de servicio que presta, se diferencia de un restaurante con menú a la carta, de una colonia de vacaciones con menú fijo o un evento con un menú estandarizado.

\section{RESTAURANTE Y BAR:}

Este departamento es el tercer pilar del área de la alimentación y bebida teniendo como funciones básicas las siguientes:

- Montaje de mesas, aparador y buffet;

- Reposición de mantelería;

- Reserva de mesas;

- Recibir y acomodar al cliente;

- Prestación del servicio;

- Facturar;

- Cambio de mantelería;

- Proponer o sugerir a cocina la oferta gastronómica;

- Informar cuando el cliente lo solicita, la composición de los platos;

- Ofrecer las sugerencias del día;

- Servicio a las habitaciones o room service;

Clasificación (basada en las características y categoría del establecimiento)

a. Room service. Es el servicio que se ofrece a un pasajero alojado en el hotel en la habitación durante las 24 horas del día;

b. Restaurante (carta -menú). Servicio de desayuno, servicio de almuerzo y cena; 
c. Salones para banquetes. Es uno de los servicios más rentables de la gastronomía hotelera y consiste en un menú predeterminado con una cantidad de comensales también determinado;

d. Restaurante - buffet. Los productos que se exponen en mesas "calientes-frías" para libre consume el cliente;

e. Restaurante - grill. Es un servicio más complejo basado en cocina autóctona, y más sofisticada;

f. Bar principal. Ofrece el servicio tanto a clientes alojados, como externos, y se encuentra habitualmente cerca de recepción.

\section{DEPARTAMENTO DE MANTENIMIENTO Y SEGURIDAD:}

Aun en aquellos casos que se contraten en forma externa la mayoría de los servicios de mantenimiento y seguridad, es importante que se desarrollen las siguientes funciones:

Mantenimiento:

- Preventivas y correctivas en relación al inmueble, instalaciones, maquinarias, mobiliario y zona exterior;

- Protección de los bienes y personas relacionadas con la actividad del hotel;

- Prevención de incendios.

Seguridad:

- Prevenir y proteger contra incendios, mediante la preparación del personal, la vigilancia constante u la inspección periódica;

- Prevenir y proteger pequeños accidentes;

- Prevenir y proteger contra robos, incorporando cajas de seguridad o tecnología moderna;

- Prevenir y proteger al personal del hotel, considerando las normas de higiene y seguridad laboral respectivas. 


\section{Relevamiento, sistematización y análisis de la normativa vigente a nivel provincial}

Normativa provincial de Alojamientos Turísticos• Buenos aires DEC. N 659/07

- Catamarca DEC. $N^{\circ} 1199 / 80$ - Ciudad de Buenos Aires Ordenanza N ${ }^{\circ}$ 36136/80 - Córdoba Ley 6483/80 DEC. $N^{\circ} 1359 / 00$ - Corrientes DEC. $N^{\circ}$ 2689/80 • Chaco Ley $\mathrm{N}^{\circ}$ 2600/81 • Chubut Ley $\mathrm{N}^{\circ} 3258 / 80$ DEC. $\mathrm{N}^{\circ} 1264$ • Entre Ríos Ley N7360 Des. N¹205. N³024/83 • Jujuy Ley N³804/81 DEC. No 777/81 • La Pampa DEC. N²686/78 • Mendoza Res. No 568/07 • Neuquén DEC. $N^{\circ} 2790 / 99$ - La Rioja DEC. N 1622/79 • Río Negro DEC. N 657/03 Res. $N^{\circ} 41 / 93$ - Salta DEC. $N^{\circ} 1125 / 80$ - San Juan Ley No 4600/79 DEC. $N^{\circ}$ 186/81 • San Luis DEC. No 3505/80 • Santa Cruz Ley No 4967/81 • Tierra del Fuego Ley N 65/93 DEC. N²621/93 y N²03/99 • Tucumán Ley N 5204/82 LEY 7484 / 2005.

En las leyes de alojamiento turístico de la Provincia de Buenos Aires y de la Ciudad de Buenos Aires son más actuales que la ley de Hotelería Nacional que está muy caduca.

La ordenanza de la Ciudad de Buenos aires contempla en su redacción el alojamiento turístico, hotel, apart hotel, hospedaje e incorpora los campamentos y los clasifica en categorías.

En cambio la Ley de la Provincia de Buenos Aires DEC 659/07 comprende al alojamiento turístico dentro del mismo entran el hotel, apart hotel, hostería, residencial a y b y cabañas y bungalows. 


\section{Marco normativo internacional (España) ${ }^{20}$}

Los Alojamientos ${ }^{21}$ turísticos han sido objeto de todo tipo de definiciones terminológicas y conceptuales que sistemáticamente han ido aportando elementos nuevos, no todos acertados ni uniformes. Quizá el único símbolo que ha unificado tanta definición haya sido el de prestación de servicios y curiosamente en los alojamientos turísticos, donde más que en ningún otro segmento del sector turístico se puede avanzar en la disquisición de su propia naturaleza: servicio o industria.

Ya en el clásico Estatuto Ordenador de Empresas y Actividades Turísticas de 1965, se profundizaba en el concepto técnico de los alojamientos turísticos, clasificándolos en los de hostelería y los de carácter no hotelero. Esta clasificación elemental se ha mantenido a lo largo de estos años y parece ser más bien un dogma que una pura y simple diferenciación técnica, jurídica o comercial.

Si para la legislación española del 65 eran hoteles las empresas dedicadas de modo profesional o habitual, mediante precio, a proporcionar habitación a las personas con o sin otros servicios de carácter complementario, para el controvertido Real Decreto de 15 de junio de 1983 son hoteles las empresas o establecimientos dedicados de modo profesional y habitual al alojamiento de personas mediante precio, teniendo la condición de establecimientos abiertos al público. Como se observa, una definición copia, veinte años después los conceptos de la primera, a los que nada aportan las recientes normativas de las Comunidades Autónomas.

\footnotetext{
${ }^{20}$ Legislación Turística de Islas Baleares.-

${ }^{21} \mathrm{http}: / / \mathrm{www}$.aedave.es.-
} 
Por su parte los alojamientos turísticos no hoteleros son albergues, campamentos, bungalows, apartamentos, ciudades de vacaciones o establecimientos similares destinados a proporcionar mediante precio, habitación o residencia a las personas en épocas, zonas o situaciones turísticas. Nunca se conocerá realmente la razón por la cual el Decreto231/1965 privó de la condición de profesionalidad a los alojamientos turísticos no hoteleros, pero lo cierto es que las reglamentaciones que a raíz de este Estatuto Ordenador surgieron sobre estos diversos tipos de alojamientos turísticos, no incorporaron novedades de fondo y forma.

La confusión de los conceptos de hostelería y alojamientos turísticos, no sólo a nivel popular, sino muchas veces a nivel profesional, ha originado un olvido $y$ semidesprecio por todas las modalidades de alojamiento no hotelero. Es cierto que el desarrollo de unos y otros ha sido muy distinto. El turismo tradicional, económicamente más fuerte y exportado desde el origen adoptaba la forma hotelera que verdaderamente representaba la más fiel imagen del alojamiento turístico español. A senso contrario, el camping, los bungalows u otros sistemas similares eran más tradicionales de otros destinos europeos.; la legislación ha procurado separar las diversas modalidades y fruto de esa separación son los reglamentos de 1983 (actual) de hostelería, 1967 y 1982 de apartamentos turísticos y bungalows, de 1966 y 1982 de campamentos de turismo y los amplísimos desarrollos legislativos llevados a cabo por las Comunidades Autónomas. Sin embargo, es cierto que la gran base del alojamiento turístico fue y es el hotel y que su estructura comercial y jurídica condiciona al resto de los alojamientos turísticos.

El hotel es una modalidad más de alojamiento turístico. Sin duda y con mucho la más importante, la más profesional y la más significativa, pero no se puede identificar con el concepto global o único de alojamiento turístico, pues sería un error discriminativo e imperdonable. 
Queremos referirnos, en breves pinceladas, a ciertos criterios técnico-jurídicos, técnico-profesionales y técnico-físicos que tienen gran relevancia en los hoteles, (sin entrar en las reglamentaciones tangenciales).

En los criterios técnico-jurídicos destaca, principalmente, el contenido intrínseco de la actividad hotelera, profundo y exclusivo, de tal manera que la normativa recoge en repetidas ocasiones su exclusión directa de la Ley de Arrendamientos Urbanos y en especial del contenido de su artículo 18.

Destaca también la estructura reglamentaria y ordenalista de la actividad, lo que se traduce en un peso sustantivo de exigencias administrativas que abarca desde cumplimientos burocráticos inagotables, hasta las autorizaciones para actuar, pasando inevitablemente por la guadaña oficial de inspecciones y sanciones. Pocas actividades económicas privadas han sido sometidas a un rigor político y administrativo tan minucioso.

Con relación a los criterios técnico-profesionales la breve historia de la hostelería española nos ha enseñado que una de las obsesiones mantenidas por la decisión política se basaba, acertadamente, en la profesionalización de todos los niveles y en especial de los niveles de mayor responsabilidad. Sin embargo los procedimientos para alcanzar esta profesionalidad dista mucho de lo que debería darse en un sistema moderno y competitivo. Señalamos tres datos como ejemplos claros: por un lado el Registro de Empresas y Actividades Turísticas (orden del 20 de noviembre de 1964) por el Estatuto de Directores de Establecimientos Turísticos (orden del 11 de agosto de 1972) y finalmente la Ordenación de las Enseñanzas Turísticas y su especial exigencia y cumplimiento para ejercer como directores de establecimientos turísticos y por ende hosteleros. Todos estos criterios en proceso de revisión, extinción o retroceso.

Finalmente, al referirnos a los criterios técnico-físicos queremos destacar los principios impuestos por la Administración para la Defensa del Consumidor y Usuario recogido en la Ley 26/1984 de 19 de julio, referente básicamente a los 
servicios prestados y recibidos, y también a los espacios privativos facilitados a las personas que contratan los servicios hoteleros: las dimensiones mínimas de las habitaciones, distintas para cada categoría de hotel e incluso distintas en cada Comunidad Autónoma.

El entorno medio ambiental sirve como colofón de los criterios técnico-físicos y en tal sentido hacer referencia a la normativa ejemplar de la Comunidad Autónoma de las Islas Baleares, acomodando el desarrollo turístico al entorno físico, al espacio y a la estética.

Han existido algunas normas sobre hospedaje en la "antigüedad". Se revisan esos criterios en las normativas a finales de siglo $(1857,1892)$ pero una historia más próxima nos lleva a la primera clasificación hotelera española que se estableció por la Orden de 8 de abril de 1939, vigente durante 18 años. Luego la Orden de 5 de noviembre de 1940 estableció el uso de la palabra turismo por albergues, paradores y similares. Si cabe duda de su derogación expresa, no cabe duda de su derogación tácita por desuso. Lo mismo ocurre con el Decreto de 4 de abril de 1952 sobre albergues y paradores.

Más cerca nos lleva al Reglamento de la Industria Hotelera (obsérvese el concepto de industria) que surge por Orden de 14 de junio de 1957. Esta Orden quedó irregularmente derogada por el Estatuto Ordenador de Empresas y Actividades Turísticas (Decreto 231/1965 de 14 de enero) quién con carácter general así lo proclama. Sin embargo fueron las Ordenes de 28 de marzo de 1966 y 19 de julio de 1968 quienes marcaron las normas concretas que no eran de aplicación, dejando vigente algunas partes de su articulado (Arts. 1 al 5 - 49 al 58 - 62 al 65 y $67)$.

Fruto de la Asamblea Nacional de Turismo, celebrada en Madrid en 1964 surgen nuevos criterios que el sector desea imponer y elevar la categoría del reglamento. Inspirada en estos criterios surge la Orden del 19 de julio de 1968 por la que se 
dictaminan normas sobre clasificación de establecimientos hoteleros, modificada posteriormente por las Órdenes del 16 de febrero de 1970, de 14 de febrero de 1971 y de 19 de junio de 1974.

Razones políticas llevaron a una nueva disposición: Real Decreto 3093/1982 de 15 de octubre que con muy escaso mordiente jurídico, resultó ineficaz. Su disposición derogatoria también se olvidaría de la vieja normativa de 1957. Poca vida tuvo este Real Decreto pues tan solo 6 meses después se promulgó el actual vigente: Real Decreto 1634/1983 de 15 de junio, en el que curiosamente también se vuelve a olvidar de la norma del 57, se demostró que la obsesión de este Real Decreto era derogar el del 82, cosa que hizo sin el oportuno análisis jurídico. La única disposición que efectúa este oportuno análisis fue el Decreto 110 de 1986 del 18 de junio de la Comunidad Autónoma de Andalucía.

El Real Decreto del 83 de aplicación nacional es solamente de aplicación real en las Comunidades Autónomas que no han generado su propia normativa, considerándose derecho supletorio en el resto de Comunidades Autónomas.

Siendo tan importante la implantación de la hostelería, pronto las Comunidades Autónomas comenzarán a reglamentarlas. El desfile normativo ha sido y es desde hace quince años constantes y promete no detenerse.

Hoy la actividad hotelera ha conseguido una posición dominante en el sector turístico. Si antaño fueron las Agencias de Viajes quienes ejercieron el liderazgo en el sector hoy son los hoteles que ven amenazado su liderazgo por las grandes compañías de transporte. A pesar de esto los gobiernos autonómicos han considerado a la actividad hotelera por encima de las otras actividades turísticas y han cuidado, casi mimado, su proceso asociativo, facilitándoles, además, su participación en la elaboración de las políticas turísticas. 
Quedan en las normativas hoteleras muchos puntos por precisar: intrusismo, calidad y atención al cliente, innovación tecnológica, responsabilidad, etc.

Las Comunidades han ido elaborando sus textos reglamentarios según sus intereses, conveniencias y oportunidades sin integrar en una política nacional común, lo que ha provocado disparidades profundas, casi hasta llegar al antagonismo ridículo.

Ridículo por lo que a la demanda repercute y ridículo por las compañías de ámbito nacional.

Parece como si hubiera elementos tan dispares que se buscasen objetivos, procedimientos, resultados o intenciones diferentes.

El análisis de la legislación autonómica que a continuación realizamos, así como el cuadro comparativo de la misma, así lo atestiguan. 


\section{Capítulo II}

\section{Normas de calidad (normas voluntarias) y normas jurídicas (normas obligatorias)}

De acuerdo con la International Organization for Stardarization (ISO), la normalización es la actividad que tiene por objeto establecer, ante los problemas reales o potenciales, disposiciones. Destinadas a usos comunes y repetido, con el fin de obtener un nivel de ordenamiento óptimo en un contexto dado que puede ser tecnológico, político o económico.-

La norma es un documento público y por lo tanto, puede ser consultada, referenciada y usada por quienes lo deseen. Su aplicación es voluntaria respecto a las normas de calidad pero en algunos casos las autoridades pueden dictar reglamentos obligatorios que hacen referencia a las normas. ${ }^{22}$

Las normas constituyen herramientas para que una organización pueda mejorar la calidad de sus productos o servicios, permitiéndole mantener y actualizar los estándares alcanzados a lo largo del tiempo, de forma tal de obtener la constante satisfacción de las necesidades del cliente, e incluso superar las expectativas de éstos. Es un documento ordenador de una cierta actividad, elaborada voluntariamente con el consenso de las partes interesadas, que contiene especificaciones técnicas extraídas de la experiencia y de los avances de la tecnología; es de público conocimiento; y, en razón de su conveniencia o necesidad de aplicación extensiva, puede ser aprobada como tal por un organismo acreditado al efecto. Las NORMAS ISO describen los requerimientos que debe satisfacer un sistema de gestión de la calidad: la estructura organizativa, las responsabilidades, los procedimientos, los procesos y los recursos necesarios para su gestión, considerando que la calidad incluye la totalidad de los aspectos y características de un producto o servicio que le confieren aptitud para satisfacer las necesidades del cliente, sean éstas establecidas o implícitas. El modelo de un sistema de gestión de la calidad basado en procesos muestra

${ }^{22}$ Guillermo Gesualdo, consultor de calidad hotelera.- 
que los clientes juegan un papel significativo para definir los requisitos como elementos de entrada. El seguimiento de la satisfacción del cliente requiere la evaluación de la información relativa a la percepción del cliente acerca de si la organización ha cumplido sus requisitos. El grupo de Normas ISO 9.000, cuya primera edición data del año 1.987, proporciona a las organizaciones una metodología para el mejoramiento de la calidad y de la eficiencia de los procesos productivos. Han sido adoptadas por más de setenta países como normas de calidad nacional; en Argentina comenzaron a certificarse en el año 1.982 .

Veamos ahora el campo jurídico y en este sentido según nos enseña el Dr. Georg Henrik Von Wright en su obra Norma y Acción la palabra inglesa norma y las que le son equivalentes en otras lenguas, se usa en muchos sentidos y a menudo con un significado poco claro. Existen varios sinónimos parciales de "norma", todos ellos ingle correcto. "Patrón ( Pattern) modelo ( standart), reglamente ( regulation), regla ( rule) y ley ( law)". Las instrucciones sobre el uso y las ordenes quizá no sea frecuente que se les llame "normas", pero es indudable que no vacilaríamos en llamarles "normativas".

Puesto que el campo de significación de " norma " no es solo es heterogéneo, sino que además tiene fronteras vagas, resultaría inútil hacer una Teoría General de las Normas que abarcara a todas. ${ }^{23}$

Las leyes del Estado son prescriptivas. Establecen reglamentos para la conducta e intercambio humanos. Su finalidad es influenciar la conducta... Cuando los hombres desobedecen las leyes, la autoridad que las respalda trata, por lo pronto, de corregir la conducta de los hombres. En ocasiones, sin embargo la autoridad cambia las leyes para hacerlas más conformes con las capacidades y exigencias de la naturaleza humana.

“Técnicamente se denomina campo obligatorio al de las normas jurídicas y campo voluntario a las normas como las ISO, IRAM SECTUR. Ambos campos deben entenderse como complementarios y no como compartimientos estancos.

Las normas voluntarias se pueden convertir en obligatorias si se incluyen en un marco jurídico obligatorio.-

"Ya no es posible permitirse no normalizar. Aún en las áreas más incipientes de la ciencia el mercado exige la normalización"

${ }^{23}$ Norma y Acción Georg Hernik Von Wright Ed. Tecnos, 1979 
"Normalizar es codificar un procedimiento para resolver un problema que se repite con frecuencia, ordenando sus datos con un criterio unificado y lógico y garantizando la solución." 24

En una visión más amplia la normalización se define como la "la forma de aplicar y establecer reglas (normas) con el fin de poner en orden un campo de actividad determinado, con el interés y concurso de todos los sectores afectados" 25

El Dr. Gonzalo Casanova Ferro expresa las normas jurídicas pueden surgir de una necesidad política, administrativa pero siempre es el órgano administrativo quien las impulsa, sanciona y promulga, de forma tacita o expresa, las normas de calidad en cambio se plantean desde la necesidad de una parte interesada e involucrada directamente con la actividad que se trate. ${ }^{26}$

Ahora bien si partimos del concepto que una norma jurídica es una pauta de conducta obligatoria tiene poco que ver con las de calidad pero para que las normas de calidad estén insertas en un cuerpo jurídico se tiene que aprobar por consenso.

\section{Principios de las ISO y normas IRAM}

\section{Principios que inspiran ISO 9001}

Los Principios que inspiran el modelo de gestión de la calidad ISO 9001:2008 se encuentran en la norma y son 8 :

1. Enfoque al cliente;

2. Liderazgo;

3. Participación del personal;

4. Enfoque basado en procesos;

5. Enfoque de sistema para la gestión;

6. Mejora continua;

7. Enfoque basado en hechos para la toma de decisiones;

\footnotetext{
${ }^{24}$ Normas de Calidad, Responsabilidad Social y Turismo-Adriana Norma Martinez y Adriana Rosenfed-Ediciones Ladevi

${ }^{25}$ Normas de Calidad, Responsabilidad social y turismo

26 Normas Juridicas y Normas de Calidad - Dr. Gonzalo Casanova Ferro - Conferencias \&Ponencias 1er Congreso Iberoamericano del Derecho del Turismo.-
} 
8. Relaciones mutuamente beneficiosas con el proveedor.

Dado que las explicaciones que se dan al respecto de cada principio no son muy extensas, este artículo pretende ampliar o aportar un punto de vista sobre la esencia de cada principio.

\section{Enfoque al cliente}

La razón de ser de las organizaciones son sus clientes, sin clientes una organización no tiene sentido.

Una vez que se ha determinado quién es el cliente de la organización (no tiene por qué ser necesariamente una persona), se debe diseñar un sistema desde su perspectiva, analizar lo que necesita y diseñar un sistema adaptado y adaptable.

Hay que tener en cuenta que actualmente el concepto de cliente se ha extendido mucho. Una organización convencional, como puede ser una empresa con ánimo de lucro, tiene más clientes que aquellos a los que destina sus productos. El medio ambiente o la salud de sus trabajadores también son clientes de la empresa actual, al igual que los organismos públicos o los accionistas.

\section{Liderazgo}

El concepto de liderazgo está intrínsecamente asociado al de organización.

Para que una organización funcione hace falta que sus líderes visualicen lo que quieren hacer, que tengan una idea más allá de qué vamos a hacer esta mañana.

Las estrategias las desarrolla el equipo directivo, los que toman las decisiones al más alto nivel, y deben asumir ellos el papel de líder de la organización.

Un líder no debe entenderse como una persona que da órdenes, sino como una persona que tiene claro lo que se ha de hacer y que sirve de guía a los demás. La consecución de los objetivos de la organización es tanto más exitosa cuanto mejores son sus líderes. El mejor líder es aquel que asume sus responsabilidades de forma natural (no forzada), y que su autoridad es aceptada también de forma natural por aquellos que deben seguirle. 


\section{Participación del personal}

Las personas son una parte muy importante de la organización, y conforme vaya avanzando el siglo XXI este aspecto será aún más importante. Contar con buenos profesionales se revela como un aspecto decisivo, pero contar con sus capacidades al servicio de la organización lo es aún más. La motivación y la iniciativa de los componentes de la organización es un activo intangible que no se puede comprar con dinero y que a la organización le puede brindar los mejores beneficios. Así pues, los diseñadores del sistema deben dedicar gran parte de sus esfuerzos a conseguir elevar día a día el porcentaje de las capacidades que sus componentes ponen a disposición de la organización.

\section{Enfoque basado en procesos}

Los resultados los proporcionan los procesos, no los departamentos, secciones, o áreas de una organización. Para servir un pedido a tiempo basta con realizar las actividades necesarias antes de que finalice el plazo de entrega. Tanto la planificación como los procedimientos a aplicar deben establecerse en función de los procesos a ejecutar. El análisis de los procesos y su secuencia debe proporcionar información para definir cómo queremos que sean las entradas y salidas de los procesos que están interrelacionados, qué recursos necesitan, cómo los vamos a controlar... ISO 9001:2008 desarrolla este concepto en sus "Requisitos generales".

\section{Enfoque de sistema para la gestión}

Un sistema de gestión está formado por un conjunto de procesos relacionados, ejecutados bajo unas condiciones especificadas (los procedimientos), siguiendo la estrategia establecida por sus líderes... pero además está rodeada por multitud de elementos que forman parte de su universo: clientes, proveedores, el medio ambiente, la sociedad, instituciones públicas, agentes sociales, un marco jurídico... La organización es un organismo que depende y tiene su razón de ser fuera de ella. Debe conjugar sus necesidades con las necesidades de su entorno, 
debe adaptarse, evolucionar... El sistema de gestión debe verse desde una perspectiva global, ver más allá de las fronteras.

\section{Mejora continua}

La autosatisfacción está reñida con la calidad. La organización debe realizar esfuerzos continuados por ser mejor, ya que una organización que no evoluciona hacia la mejora de todas sus partes, inexorablemente cambiará a peor (su calidad disminuirá con el tiempo). El contexto de las organizaciones está en continuo cambio, lo que antes al cliente le parecía bien, ahora no lo es. La mejora de las organizaciones está relacionada con la mejora de nuestro nivel de vida. La mejora continua en el desempeño global de la organización debería ser un objetivo permanente de toda empresa. El modelo ISO 9001:2000 desarrolla con amplitud el concepto de mejora continua definiendo un proceso de mejora continua basado en el establecimiento de una estrategia (Política -> Objetivos), la acciones para conseguir los objetivos, recogida de datos, análisis, revisión...

\section{Enfoque basado en hechos para la toma de decisiones}

La toma de decisiones basadas en suposiciones conllevan un riesgo elevado, ya que es añadir incertidumbre a un acto que ya es de por si arriesgado: decidir. Las organizaciones deben contar con un sistema de gestión que genere información de forma natural (sin esfuerzo suplementario) y que su tratamiento permita extraer conclusiones acerca de la situación real de la organización y su entorno. En la época de la información, una organización no debe permitirse el lujo de renunciar a ella o desaprovecharla. Cuanto mejor sea la información mejores serán las decisiones.

\section{Relaciones mutuamente beneficiosas con el proveedor}

En la relación con los proveedores, las tensiones, disputas y enfrentamientos no rendirán nunca beneficios, sino pérdidas. Las organizaciones deben esforzarse por establecer relaciones de mutua confianza con sus proveedores ya que esta 
situación aumenta la capacidad de ambos para crear valor. Las dificultades de los proveedores repercuten negativamente tarde o temprano en los clientes de éstos.

Ofrecieran "hospedaje o alojamiento en habitaciones amuebladas por periodos no menores al de pernoctación a personas que no constituyan domicilio permanente en ellos"

\section{Los sistemas de gestión integrada de la calidad}

Un Sistema de Gestión de la Calidad (SGC) es un método de trabajo por el cual se asegura la conformidad de los productos y servicios con los requisitos especificados. Un Sistema de Gestión de Calidad (SGC) consta de dos partes: 1. una parte escrita, que consiste en una serie de documentos en los cuales se describe el sistema, los procedimientos, las instrucciones y los planos, ajustándose a una norma;

2. Una parte práctica que se compone de dos variables: a) los aspectos físicos, tales como los locales, las maquinarias, los instrumentos de control, etc.; b) los aspectos humanos, tales como el adiestramiento en técnicas de calidad del personal de todos los niveles jerárquicos, a fin de crear un equipo motivado y cooperador cuyas actitudes positivas ayuden a desarrollar el proyecto.

Modelo de un SGC basado en procesos 


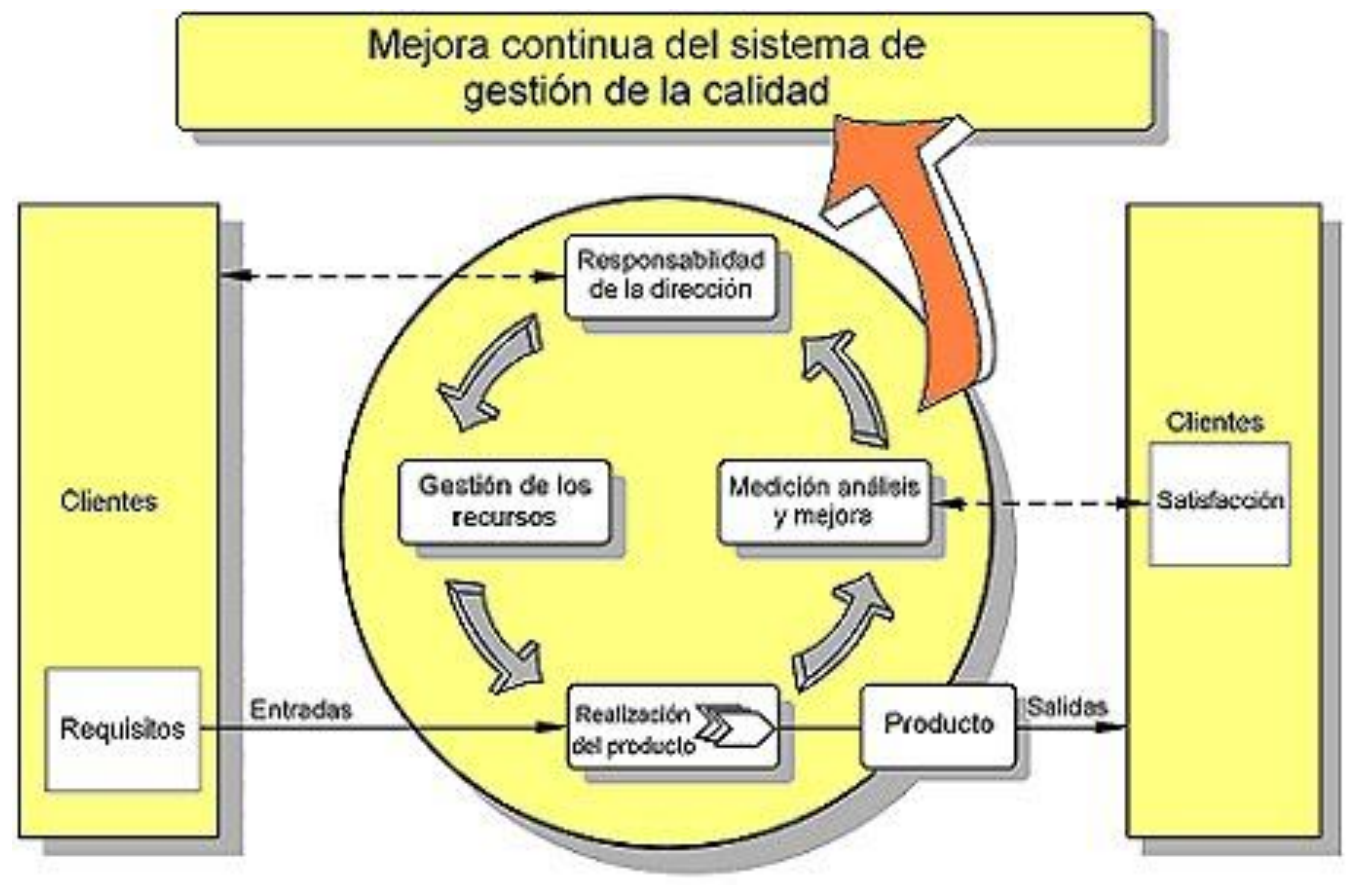

Leyenda

Actividades que aportan valor

Flujo de información

Fuente: Guillermo Gesualdo (Consultor en calidad hotelera) 


\section{Capítulo III}

\section{Calidad en el sector hotelero}

Roberto Boullon en su obra Calidad Turística nos habla que la obtención de la calidad en los servicios turísticos se complica porque conceptualmente no han quedado suficientemente claras las fronteras que separan la aplicación de este concepto en el campo de los productos de fabricación industrial en cantidades masivas de la producción de servicios y dentro de estos al turismo.

Tres son las premisas aptas para describir el fenómeno en el campo del turismo y ensayar las soluciones y métodos para aplicarlo.

1-Lograr la calidad en el campo del turismo no fácil. Si bien cada servicio es un todo, cada uno de ellos intervienen muchas personas y cosas.

2-En la esfera privada la calidad es responsabilidad de toda la organización, no solo de aquellos que están en contacto con el cliente

3- El empresario planifica y dirige, los programas de calidad, sus empleados los ponen en práctica pero el único que la juzga es el cliente

Un empresario hotelero al ser consultado por la implementación de las buenas prácticas en su establecimiento contesto: "lo que impulsó a implementar la calidad en nuestro establecimiento no fue el programa Buenas Prácticas. Desde que me hice cargo del establecimiento a fines del año 1996 se impulsó un sistema de gestión, control, capacitación exhaustiva del personal, involucrando a los mismos en las actividades con reuniones constantes de control y mejora del servicio en cada uno de los sectores etc. Lo que si nos brindo Bs Prácticas fue la estructuralización del sistema, manteniendo nota en libros de las reuniones y los puntos a charlar etc. Cosa que antes lo hacíamos en forma oral sin registro alguno. Si se escribía si las necesidades en hojas móviles que luego una vez resuelto desaparecían. Los planes de Mejoras, los manuales de operaciones (existentes solo para ciertos sectores y para actividades específicas) hoy es para 
todos y para todos los sectores y actividades. Bueno nos fue muy bien, ya que distinguimos y estamos en proceso de revalidación del mismo. Y con el personal se encuentra más motivado que nunca, con un alto grado de participación en los procesos, ya que las rutinas y las reglas generan seguridad.

La ventas no le podría decir que aumentaron pero si los clientes cuando ven la placa en la recepción, notan los procesos que tenemos se sienten más cómodos, seguros y eso hace que tengan una buena estadía y que regresen, se fidelicen con nuestro establecimiento.

El Hotel Intercontinental es el único hotel que tiene premio nacional a la calidad y el gerente del hotel ha dicho: "En el hotel la calidad en el servicio al cliente es una estrategia de comercialización que ha sido privilegiado desde los orígenes mismos de la organización. Reconocido como "hotel escuela" por su compromiso con la mejora continua en su entramado diario, ocupa un lugar de relevancia el concepto de Calidad Total. Por lo mismo la obtención de una distinción formal de calidad ha significado para el INTERCONTINENTAL un reconocimiento al esfuerzo de nuestros trabajadores y la comprobación formal de nuestras prácticas comerciales exitosas que ameritan que clientes de todo el mundo prefieran establecerse en nuestro hotel"

\section{Relevamiento de la oferta hotelera}

La industria turística se caracteriza por tener estructura muy específica que condicionan fuertemente la oferta de alojamiento. El sector de la hotelería, particularmente, responde tanto a las características de la industria pesada como a la de la industria artesanal. Se la asocia a la industria pesada por la magnitud de las inversiones a efectuar y por el capital a movilizar en el mediano y largo plazo, es decir durante la fase de construcción de inmuebles.

Por otra parte, tiene las características de la industria artesanal por la actividad de servicios propia del funcionamiento de los hoteles y por el elevado nivel de empleo por habitación, en particular en aquellos establecimientos de categoría alta. 
Para la Asociación Internacional de Hotelería (1953) «un hotel de turismo es una empresa de alojamiento destinada a recibir huéspedes que se proponen hacer allí una permanencia temporaria, y a la cual se agrega generalmente una empresa de restaurante».

Los hoteles se han convertido en una actividad económica importante. Además, crea empleos directos e indirectos, son una fuente significativa de entrada de divisas. Puede ser explotado durante todo el año o solo en temporada.

El concepto de hospedaje fue evolucionando a través del tiempo. Los cambios en las formas de vivir, viajar y de hacer turismo han provocado modificaciones y diversificaciones en las modalidades de alojamiento que hoy son numerosas.

Las empresas hoteleras se dividen en dos grupos: las grandes y las pequeñas.

Las grandes y medianas son hoteles, moteles y apart hotel. Todos ellos pueden pertenecer a cadenas hoteleras internacionales o nacionales, o no. Su clasificación más usual y adoptada en la Argentina, es la taxonomía de 1 a 5 estrellas de acuerdo al tamaño y cantidad de servicios que ofrece, hecho que se encuentra en estrecha relación con los recursos físicos, tecnológicos y humanos.

Para 1998, se encontraban registrados 7.738 establecimientos hoteleros de los cuales 2.483 correspondían a hoteles de 1 a 5 estrellas, aparthotel y el resto pertenecían a otras formas de alojamiento. Según la Secretaría de Turismo esta última incluía a residenciales, hosterías, hospedajes, moteles, hostales, pensiones, refugios, posadas, estancias, cabañas, bungalow y hoteles sin categorizar, corresponden a nuestra clasificación al grupo de pequeñas empresas. 
Oferta y demanda hotelera, indicadores seleccionados por mes y tipo de establecimiento. Ciudad Autónoma de Buenos Aires. Año $2011^{27}$

\begin{tabular}{|c|c|c|c|c|c|}
\hline \multirow{2}{*}{$\begin{array}{c}\text { Indicadores } \\
\text { seleccionados por tipo } \\
\text { de establecimiento }\end{array}$} & \multicolumn{5}{|c|}{2011} \\
\hline & Enero & Febrero & Marzo & Abril & Mayo* \\
\hline \multicolumn{6}{|l|}{ Establecimientos (1) } \\
\hline Total & 670 & 669 & 671 & 672 & 674 \\
\hline Hoteleros & 388 & 388 & 391 & 391 & 394 \\
\hline Hotel 5 estrellas & 23 & 23 & 23 & 23 & 23 \\
\hline Hotel 4 estrellas & 72 & 73 & 74 & 75 & 76 \\
\hline Hotel 3 estrellas & 64 & 64 & 64 & 63 & 62 \\
\hline Apart hotel & 56 & 56 & 58 & 58 & 62 \\
\hline Hotel boutique & 78 & 77 & 77 & 77 & 76 \\
\hline \multicolumn{6}{|l|}{ Hotel 1 y 2} \\
\hline estrellas & 95 & 95 & 95 & 95 & 95 \\
\hline Para-hoteleros & 282 & 281 & 280 & 281 & 280 \\
\hline Hostel & 125 & 125 & 124 & 124 & 123 \\
\hline Resto & 157 & 156 & 156 & 157 & 157 \\
\hline
\end{tabular}

\section{Habitaciones o}

\section{unidades disponibles}

(2)

$\begin{array}{crrrrr}\text { Total } & \mathbf{8 8 9 . 6 2 8} & \mathbf{8 0 3 . 0 1 2} & \mathbf{8 9 5 . 6 2 7} & \mathbf{8 6 9 . 8 6 6} & \mathbf{9 0 3 . 6 8 1} \\ \text { Hoteleros } & \mathbf{7 4 9 . 7 5 6} & \mathbf{6 7 7 . 6 0 0} & \mathbf{7 5 7 . 3 9 8} & \mathbf{7 3 4 . 4 0 6} & \mathbf{7 6 4 . 3 0 5} \\ \text { Hotel 5 estrellas } & 161.448 & 145.404 & 162.502 & 157.080 & 162.068 \\ \text { Hotel 4 estrellas } & 214.830 & 194.488 & 220.689 & 216.900 & 227.044 \\ \text { Hotel 3 estrellas } & 132.277 & 120.260 & 132.525 & 127.080 & 128.309 \\ \text { Apart hotel } & 74.927 & 67.732 & 76.601 & 73.980 & 80.755 \\ \text { Hotel boutique } & 42.429 & 37.548 & 41.918 & 40.776 & 42.067\end{array}$

${ }^{27}$ Instituto de Estadísticas y Censo de la Nación 
Hotel 1 y 2

estrellas

Para-hoteleros

Resto

$\begin{array}{lllll}123.845 & 112.168 & 123.163 & 118.590 & 124.062 \\ \mathbf{1 3 9 . 8 7 2} & \mathbf{1 2 5 . 4 1 2} & \mathbf{1 3 8 . 2 2 9} & \mathbf{1 3 5 . 4 6 0} & \mathbf{1 3 9 . 3 7 6} \\ 139.872 & 125.412 & 138.229 & 135.460 & 139.376\end{array}$

\section{Habitaciones o}

unidades ocupadas (3)

Total

\section{Hoteleros}

Hotel 5 estrellas

Hotel 4 estrellas

Hotel 3 estrellas

Apart hotel

Hotel boutique

Hotel 1 y 2

estrellas

Para-hoteleros

Resto

Plazas disponibles (4)

Total

Hoteleros

Hotel 5 estrellas

Hotel 4 estrellas

Hotel 3 estrellas

Apart hotel

Hotel boutique

Hotel 1 y 2

estrellas

Para-hoteleros

Hostel

Resto

$\begin{array}{rrrrr}\mathbf{4 9 2 . 1 0 8} & \mathbf{4 4 6 . 1 5 5} & \mathbf{5 4 7 . 3 3 3} & \mathbf{5 3 2 . 5 8 3} & \mathbf{5 1 0 . 1 8 5} \\ \mathbf{4 4 3 . 9 6 9} & \mathbf{3 9 9 . 4 5 6} & \mathbf{4 9 5 . 3 9 5} & \mathbf{4 7 8 . 9 8 4} & \mathbf{4 5 3 . 9 5 7} \\ 109.297 & 105.895 & 126.969 & 115.754 & 109.104 \\ 138.771 & 119.517 & 150.391 & 149.019 & 140.910 \\ 75.941 & 63.979 & 80.646 & 79.670 & 73.374 \\ 48.239 & 40.435 & 50.014 & 48.785 & 49.071 \\ 24.118 & 22.205 & 26.995 & 25.110 & 21.581 \\ & & & & \\ 47.603 & 47.425 & 60.380 & 60.646 & 59.917 \\ \mathbf{4 8 . 1 3 9} & \mathbf{4 6 . 6 9 9} & \mathbf{5 1 . 9 3 8} & \mathbf{5 3 . 5 9 9} & \mathbf{5 6 . 2 2 8} \\ 48.139 & 46.699 & 51.938 & 53.599 & 56.228\end{array}$

$\begin{array}{rrrrr}\mathbf{2 . 0 6 0 . 8 2 2} & \mathbf{1 . 8 6 1 . 9 7 2} & \mathbf{2 . 0 7 5 . 8 2 7} & \mathbf{2 . 0 1 6 . 3 0 3} & \mathbf{2 . 0 9 7 . 4 6 0} \\ \mathbf{1 . 6 2 6 . 2 7 1} & \mathbf{1 . 4 7 1 . 9 6 0} & \mathbf{1 . 6 4 7 . 3 1 4} & \mathbf{1 . 5 9 8 . 2 2 9} & \mathbf{1 . 6 6 1 . 7 5 5} \\ 321.687 & 289.716 & 323.795 & 312.990 & 323.237 \\ 449.066 & 406.476 & 460.226 & 452.310 & 475.261 \\ 297.291 & 268.492 & 297.135 & 284.700 & 288.176 \\ 192.882 & 178.864 & 201.345 & 195.000 & 209.126 \\ 90.344 & 79.716 & 89.099 & 86.559 & 89.404 \\ & & & & \\ 275.001 & 248.696 & 275.714 & 266.670 & 276.551 \\ \mathbf{4 3 4 . 5 5 1} & \mathbf{3 9 0 . 0 1 2} & \mathbf{4 2 8 . 5 1 3} & \mathbf{4 1 8 . 0 7 4} & \mathbf{4 3 5 . 7 0 5} \\ 135.804 & 123.564 & 134.726 & 132.960 & 136.338 \\ 298.747 & 266.448 & 293.787 & 285.114 & 299.367\end{array}$


Plazas ocupadas (5)

Total

\section{Hoteleros}

Hotel 5 estrellas

Hotel 4 estrellas

Hotel 3 estrellas

Apart hotel

Hotel boutique

Hotel 1 y 2

estrellas

Para-hoteleros

Hostel

Resto

$\begin{array}{rrrrr}\mathbf{9 3 7 . 4 4 8} & \mathbf{8 2 4 . 5 2 4} & \mathbf{1 . 0 0 0 . 1 1 6} & \mathbf{9 8 9 . 6 2 7} & \mathbf{9 0 6 . 4 9 3} \\ \mathbf{7 9 3 . 1 0 1} & \mathbf{6 8 7 . 2 9 2} & \mathbf{8 4 9 . 4 1 5} & \mathbf{8 3 9 . 4 4 6} & \mathbf{7 6 4 . 1 1 1} \\ 173.101 & 158.711 & 185.346 & 180.498 & 156.246 \\ 241.455 & 198.806 & 251.780 & 250.830 & 229.983 \\ 141.450 & 115.940 & 148.036 & 145.570 & 132.975 \\ 101.168 & 81.573 & 97.930 & 96.778 & 93.740 \\ 43.875 & 39.873 & 48.538 & 45.559 & 36.574\end{array}$

$\begin{array}{lllll}92.052 & 92.389 & 117.785 & 120.211 & 114.593\end{array}$

$\begin{array}{lllll}144.347 & 137.232 & 150.701 & 150.181 & 142.382\end{array}$

$\begin{array}{lllll}59.921 & 56.358 & 56.437 & 56.022 & 40.386\end{array}$

$\begin{array}{lllll}84.426,00 & 80.874,00 & 94.264,00 & 94.159,00 & 101.996,00\end{array}$

\section{Porcentaje de \\ ocupación de las \\ habitaciones o \\ unidades (6)}

Total

Hoteleros

Hotel 5 estrellas

Hotel 4 estrellas

Hotel 3 estrellas

Apart hotel

Hotel boutique

Hotel 1 y 2

estrellas

Para-hoteleros

Resto $\begin{array}{lllll}55,32 & 55,56 & 61,11 & 61,23 & 56,46\end{array}$

$\begin{array}{lllll}59,22 & 58,95 & 65,41 & 65,22 & 59,39\end{array}$

$\begin{array}{lllll}67,7 & 72,83 & 78,13 & 73,69 & 67,32\end{array}$

$64,6 \quad 61,45 \quad 68,15 \quad 68,7 \quad 62,06$

$\begin{array}{lllll}57,41 & 53,2 & 60,85 & 62,69 & 57,19\end{array}$

$\begin{array}{lllll}64,38 & 59,7 & 65,29 & 65,94 & 60,77\end{array}$

$\begin{array}{lllll}56,84 & 59,14 & 64,4 & 61,58 & 51,3\end{array}$

$38,44 \quad 42,28 \quad 49,02 \quad 51,14 \quad 48,3$

$\begin{array}{lllll}\mathbf{3 4 , 4 2} & \mathbf{3 7 , 2 4} & \mathbf{3 7 , 5 7} & \mathbf{3 9 , 5 7} & \mathbf{4 0 , 3 4}\end{array}$

$\begin{array}{lllll}34,42 & 37,24 & 37,57 & 39,57 & 40,34\end{array}$

Porcentaje de ocupación de plazas

(7) 


\section{Total}

Hoteleros

Hotel 5 estrellas

Hotel 4 estrellas

Hotel 3 estrellas

Apart hotel

Hotel boutique

Hotel 1 y 2

$$
\text { estrellas }
$$

Para-hoteleros

Hostel

Resto

$\begin{array}{lllll}\mathbf{4 5 , 4 9} & \mathbf{4 4 , 2 8} & \mathbf{4 8 , 1 8} & \mathbf{4 9 , 0 8} & \mathbf{4 3 , 2 2} \\ \mathbf{4 8 , 7 7} & \mathbf{4 6 , 6 9} & \mathbf{5 1 , 5 6} & \mathbf{5 2 , 5 2} & \mathbf{4 5 , 9 8} \\ 53,81 & 54,78 & 57,24 & 57,67 & 48,34 \\ 53,77 & 48,91 & 54,71 & 55,46 & 48,39 \\ 47,58 & 43,18 & 49,82 & 51,13 & 46,14 \\ 52,45 & 45,61 & 48,64 & 49,63 & 44,82 \\ 48,56 & 50,02 & 54,48 & 52,63 & 40,91\end{array}$

$33,47 \quad 37,15 \quad 42,72 \quad 45,08 \quad 41,44$

$\begin{array}{lllll}33,22 & 35,19 & 35,17 & 35,92 & 32,68\end{array}$

$\begin{array}{lllll}44,12 & 45,61 & 41,89 & 42,13 & 29,62\end{array}$

$\begin{array}{lllll}28,26 & 30,35 & 32,09 & 33,03 & 34,07\end{array}$

\section{Viajeros (8)}

\section{Total}

\section{Hoteleros}

Hotel 5 estrellas

Hotel 4 estrellas

Hotel 3 estrellas

Apart hotel

Hotel boutique

Hotel 1 y 2

estrellas

Para-hoteleros

Hostel

Resto

$\begin{array}{rrrrr}\mathbf{3 7 7 . 8 2 1} & \mathbf{3 4 4 . 4 9 6} & \mathbf{4 2 0 . 4 8 9} & \mathbf{4 1 4 . 2 1 3} & \mathbf{3 8 3 . 9 6 5} \\ \mathbf{3 2 9 . 2 7 4} & \mathbf{2 9 6 . 6 0 2} & \mathbf{3 6 7 . 7 0 2} & \mathbf{3 6 3 . 4 2 2} & \mathbf{3 3 5 . 8 8 0} \\ 74.711 & 72.027 & 85.797 & 80.133 & 71.549 \\ 102.687 & 88.521 & 111.721 & 109.373 & 102.588 \\ 57.052 & 51.024 & 65.059 & 62.766 & 58.042 \\ 37.837 & 30.312 & 36.761 & 36.233 & 34.858 \\ 18.497 & 17.385 & 20.568 & 20.174 & 15.430 \\ & & & & \\ 38.490 & 37.333 & 47.796 & 54.743 & 53.413 \\ \mathbf{4 8 . 5 4 7} & \mathbf{4 7 . 8 9 4} & \mathbf{5 2 . 7 8 7} & \mathbf{5 0 . 7 9 1} & \mathbf{4 8 . 0 8 5} \\ 16.614 & 15.245 & 16.296 & 14.500 & 11.305 \\ 31.933 & 32.649 & 36.491 & 36.291 & 36.780\end{array}$

\section{Duración de estadía}

promedio de los

turistas (en días)(9)

Total

Hoteleros

Hotel 5 estrellas

$\begin{array}{rrrrr}\mathbf{2 , 4 8} & \mathbf{2 , 3 9} & \mathbf{2 , 3 8} & \mathbf{2 , 3 9} & \mathbf{2 , 3 6} \\ \mathbf{2 , 4 1} & \mathbf{2 , 3 2} & \mathbf{2 , 3 1} & \mathbf{2 , 3 1} & \mathbf{2 , 2 7} \\ 2,32 & 2,2 & 2,16 & 2,25 & 2,18\end{array}$




\begin{tabular}{lrrrrr} 
Hotel 4 estrellas & 2,35 & 2,25 & 2,25 & 2,29 & 2,24 \\
Hotel 3 estrellas & 2,48 & 2,27 & 2,28 & 2,32 & 2,29 \\
Apart hotel & 2,67 & 2,69 & 2,66 & 2,67 & 2,69 \\
Hotel boutique & 2,37 & 2,29 & 2,36 & 2,26 & 2,37 \\
Hotel 1 y 2 & & & & & \\
estrellas & 2,39 & 2,47 & 2,46 & 2,2 & 2,15 \\
Para-hoteleros & $\mathbf{2 , 9 7}$ & $\mathbf{2 , 8 7}$ & $\mathbf{2 , 8 5}$ & $\mathbf{2 , 9 6}$ & $\mathbf{2 , 9 6}$ \\
Hostel & 3,61 & 3,7 & 3,46 & 3,86 & 3,57 \\
Resto & 2,64 & 2,48 & 2,58 & 2,59 & 2,77 \\
\hline
\end{tabular}

(1) Los establecimientos hoteleros son aquellos categorizados como hoteles 1, 2, 3, 4 y 5 estrellas y apart-hoteles. Los establecimientos para-hoteleros incluyen: hoteles sindicales, albergues, cabañas, bungalows, hospedajes, bed \& breakfast, hosterías, residenciales, etc. (2) Se considera habitación a todo cuarto o espacio amoblado ofrecido por un hotel, hostería, hospedaje o residencial, por un cierto precio por noche. Se consideran unidades los departamentos, cabañas o bungalows equipados que un establecimiento ofrece, otorgándole además algunos de los servicios de la hotelería. Las habitaciones y unidades disponibles están multiplicadas por la cantidad de días que se encuentra abierto cada establecimiento.

(3) Se refiere al total de habitaciones y/o unidades que hayan sido alquiladas/vendidas en el mes de referencia. Resulta de multiplicar el total de habitaciones ocupadas por la cantidad de noches en que fueron ocupadas las mismas.

(4) Las plazas disponibles son el número total de camas fijas y supletorias. Una cama matrimonial se contabiliza como 2 plazas. Están multiplicadas por la cantidad de días que se encuentra abierto cada establecimiento.

(5) Se refiere al total de noches que cada viajero permaneció en una habitación. Se obtiene de multiplicar la cantidad de viajeros por la cantidad de noches que cada uno se haya alojado en el establecimiento. (6) (Habitaciones o unidades ocupadas / 
Habitaciones o unidades disponibles) $* 100$

(7) (Plazas ocupadas / Plazas

disponibles) $* 100$

(8) Se considera viajero a toda persona que se ha trasladado de su lugar de residencia habitual por razones de diversa índole, tales como el ocio, los negocios, la visita a familiares o amigos, etc.; que realiza una o más pernoctaciones seguidas en el mis

(9) Estadía promedio: plazas

ocupadas / viajeros.

Fuente: INDEC, Encuesta de Ocupación Hotelera 2011. 


\section{Sistema de gestión de calidad: normas ISO}

Requisitos para un sistema de gestión de calidad

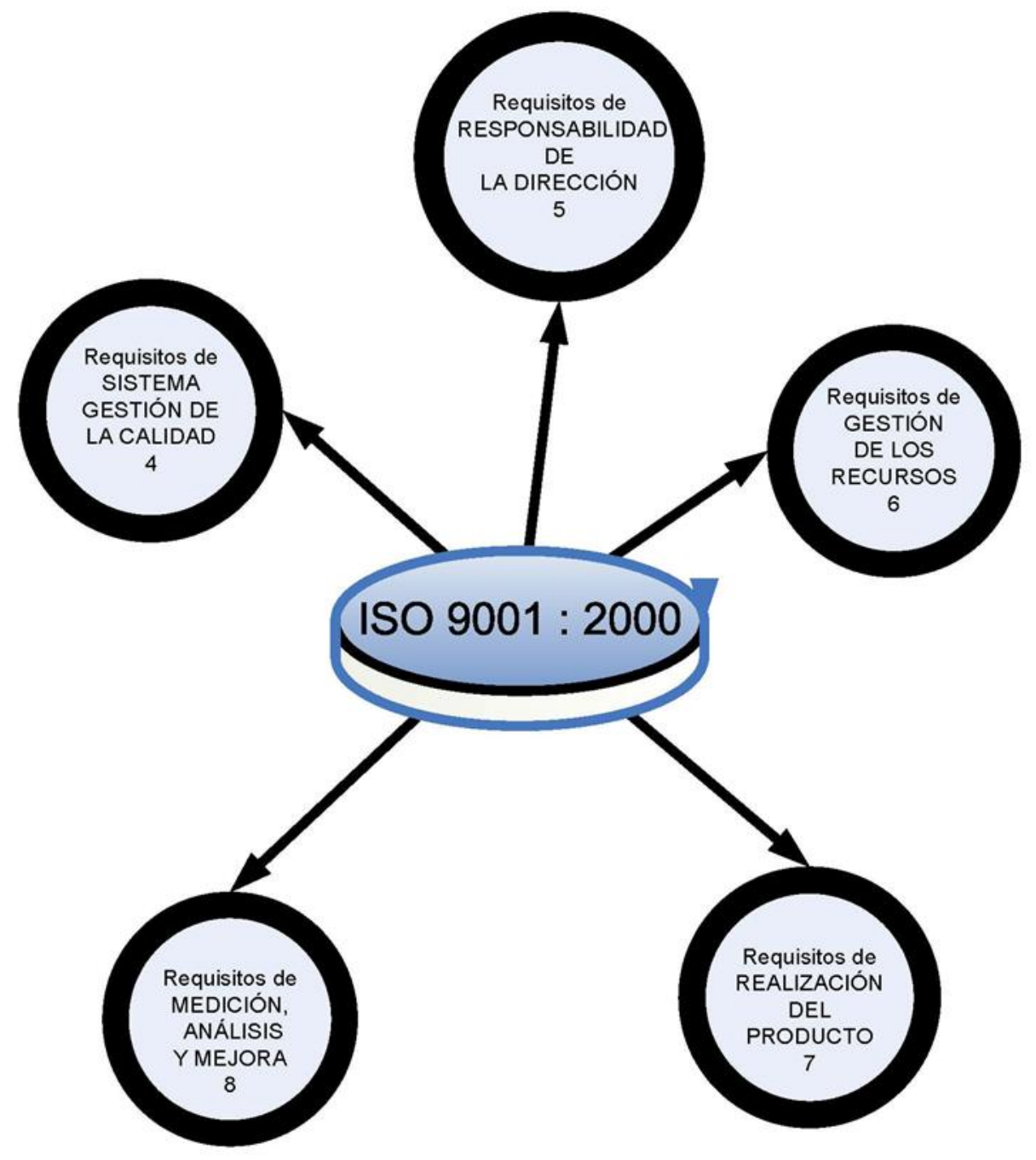

Fuente: Guillermo Gesualdo

(Consultor en calidad hotelera) 


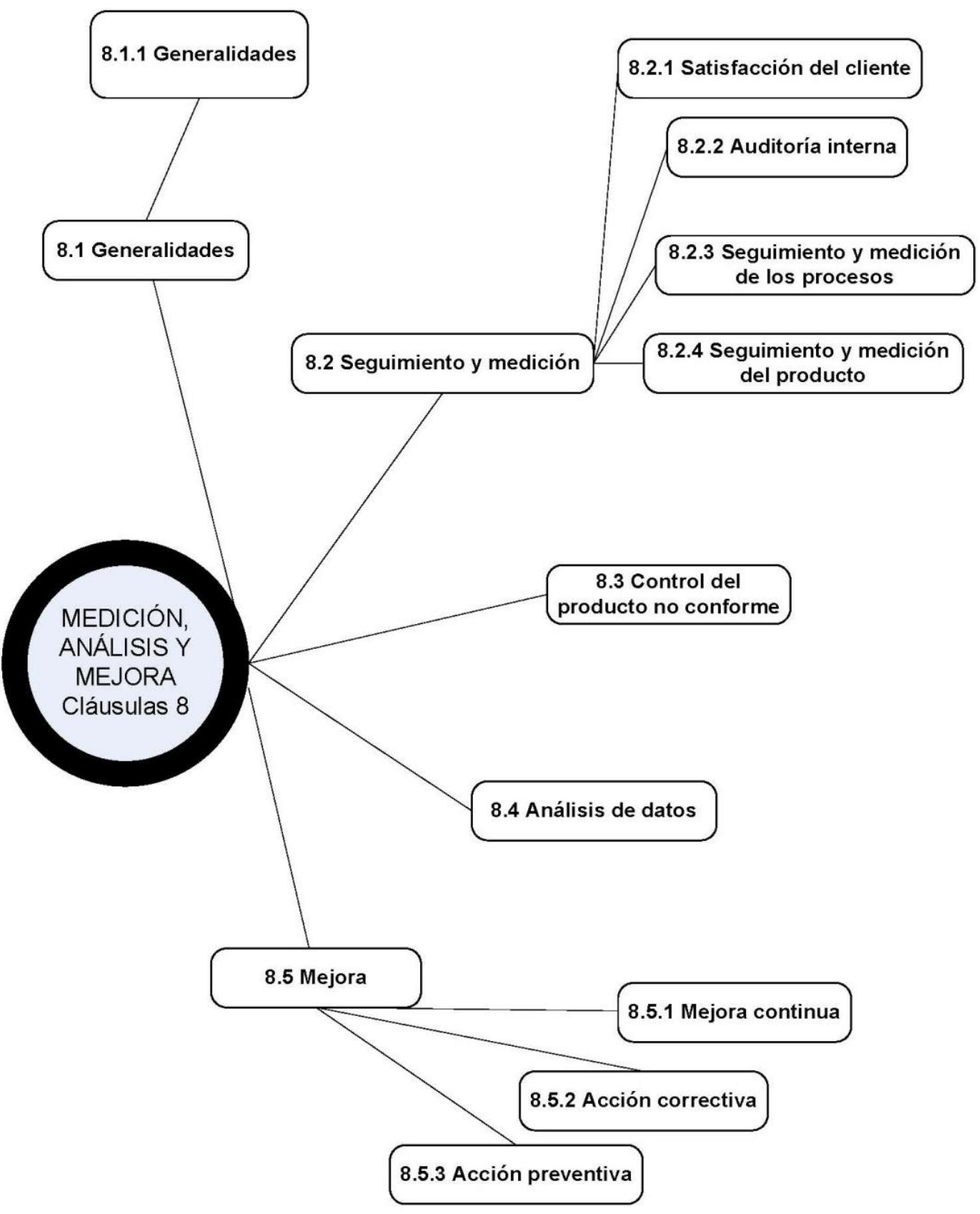

Fuente: Guillermo Gesualdo (Consultor en calidad hotelera) 


\section{Distintas normas de calidad (comparación)}

El Ministerio de Turismo ${ }^{28}$ (MINTUR) ha asumido el compromiso de difundir y expandir la cultura de la calidad y la mejora continua entre todos los actores involucrados en la prestación de servicios turísticos, por tratarse de un elemento que promueve la competitividad de los destinos.

\section{SACT}

La Dirección Nacional de Gestión de Calidad Turística ha diseñado el Sistema Argentino de Calidad Turística - SACT- consistente en un conjunto de herramientas operativas cuyo objetivo es el de promover la cultura de la calidad y la mejora continua en todos los actores que conforman la cadena de valor del sector turístico nacional.

A través del sistema se benefician tanto a destinos turísticos, como productos, incluso a sectores productivos de la actividad turística

Sus objetivos son, básicamente, desarrollar la competitividad del sistema turístico argentino a través de estándares internacionales de calidad, preservando la sustentabilidad social, económica, cultural y ambiental como así también el de implementar entre los actores del sistema un modelo de gestión por resultados mediante el diseño de procesos que respondan al cumplimiento de las misiones institucionales y que puedan ser evaluados fácilmente por los usuarios.

El SACT tiene 3 niveles: Inicial, Avanzado y de Excelencia:

- $\quad$ Nivel Inicial: SIGO (Sistema Inicial de Gestión Organizacional), Buenas Prácticas en Destinos, Directrices de Gestión, las cuales se

\footnotetext{
${ }^{28}$ Ministerio de Turismo de la Nación- Dirección de Calidad.-
} 
agrupan en: Directrices de Accesibilidad en Alojamientos Turísticos, Directrices de Accesibilidad en Servicios Turísticos, Directrices de Gestión turística y ambiental en playas y balnearios, Directrices de Gestión Turística de Municipios, Directrices para Bodegas Turísticas. Directrices de Calidad Turística para termas y Programa de Excelencia en la Gestión I.

- $\quad$ Nivel Avanzado:, Programa Excelencia en la Gestión II, Normas Sectoriales IRAM SECTUR.

- $\quad$ Nivel de Excelencia: Clubes de Excelencia, Premio Nacional a la Calidad y Programa de Excelencia en la Gestión III.

\section{Nivel inicial}

\section{SIGO (Sistema Inicial de Gestión Organizacional)}

Este sistema es una herramienta de gestión de rápida implementación destinadas a las MIPYMES del sector turístico. El objetivo del programa es conducir a las empresas hacia la modernización a través de un sistema de gestión y de estándares de calidad de nivel internacional que les permita satisfacer las necesidades cambiantes tanto del público interno como del externo. Además, el SIGO promueve la creación de condiciones necesarias para que el personal libere su potencial y realice contribuciones significativas, impulsando a la empresa a incrementar su rentabilidad y competitividad.

\section{Programa Buenas Prácticas en Destinos}

Este programa tiene por objetivo incrementar competitividad, asesorar en calidad, y conseguir generar sentimiento de pertenencia en empresas turísticas de pequeña y mediana envergadura y en organizaciones del sector público.

Además, promueve la implementación de buenas prácticas de gestión del espacio físico y de la prestación del servicio mediante la transferencia 
tecnológica de una serie de productos concebidos desde una perspectiva eminentemente práctica. Es un Programa que se realiza por Protocolo con el Gobierno Español desde el año 2006, cuya contraparte española monitorea y supervisa.

La metodología de abordaje, monitoreo y evaluación se apoya en varias actividades, entre las que podemos enumerar: sesiones de divulgación tecnológica, asistencias técnicas colectivas, talleres de divulgación por sector y asistencias técnicas individualizadas.

\section{Nivel avanzado}

\section{Normas Sectoriales IRAM-SECTUR}

A partir del convenio firmado entre el Ministerio de Turismo de la Nación y el Instituto Argentino de Normalización y Certificación (IRAM) el 14 de febrero del 2007, y producto de un intenso trabajo por parte de los talleres de normalización surgen las Normas Sectoriales IRAM-SECTUR. Estas herramientas consideran de forma integral los principales aspectos que hacen a la prestación de servicios: la gestión de la calidad, la gestión ambiental y la gestión de seguridad.

Estas normas se focalizan sobre diferentes actividades, encontrándose en un nivel avanzado de los programas de calidad, por ser bien especificas de una materia. De todas maneras, pueden agruparse en familias de normas que tienen ciertas similitudes.

Actualmente existen un total de 24 normas sectoriales, las que a continuación se detallan:

IRAM-SECTUR 42200 Hotelería

IRAM-SECTUR 42210 Cabañas

IRAM-SECTUR 42220 Casa de huéspedes (Bed and Breakfast)

\section{Nivel de excelencia}

\section{Club de excelencia}


Se considera Club de Excelencia al Grupo de establecimientos turísticos que mediante diferentes herramientas de gestión de la calidad producen y mantienen niveles de servicio por encima de la media del sector y de las expectativas de los Clientes. Estos grupos acceden a mercados rentables y selectivos a través de una marca de calidad que los agrupa, y a partir de ella, se reconocen frente a terceros.

\section{Premio Nacional a la Calidad}

El Premio Nacional a la Calidad fue instituido por Ley $N^{\circ} 24127$ para la promoción, desarrollo y difusión de los procesos y sistemas destinados al mejoramiento continuo de la calidad en los productos y servicios que se originan en el sector empresario.

Alineado con el programa de capacitación interna del Ministerio de Turismo de la Nación se inició en el 2004 el Programa de Extensión de las Bases del modelo del Premio Nacional a la Calidad para el Sector Público, que incluye dos etapas de capacitación: Sensibilización y Tutoría.

\section{Modelo EFQM ${ }^{29}$}

\section{¿Qué es el Modelo de EFQM? ${ }^{30}$}

Se trata de un modelo no normativo, cuyo concepto fundamental es la autoevaluación basada en un análisis detallado del funcionamiento del sistema de gestión de la organización usando como guía los criterios del modelo.

Esto no supone una contraposición a otros enfoques (aplicación de determinadas técnicas de gestión, normativa ISO, normas industriales específicas, etc.), sino más bien la integración de los mismos en un esquema más amplio y completo de gestión.

El Modelo EFQM permite establecer un enfoque y marco de referencia objetivo, riguroso y estructurado para el diagnóstico de la organización ${ }^{31}$. También

\footnotetext{
${ }^{29}$ Modelo efqm

${ }^{30}$ El modelo EFQM de Excelencia, Gestiñon de la Calidad de los procesos turísticos, pag 222 Ed. Sintesis
} 
proporciona una herramienta para lograr la coherencia, al establecer las líneas de mejora continua hacia las cuales deben dirigirse los esfuerzos de las organizaciones,

\section{CONCEPTOS FUNDAMENTALES:}

\section{ORIENTACIÓN HACIA LOS RESULTADOS}

La excelencia depende del equilibrio y la satisfacción de las necesidades de todos los grupos de interés relevantes para la organización (las personas que trabajan en ella, los clientes, proveedores y la sociedad en general, así como todos los que tienen interés económico en la organización).

\section{ORIENTACIÓN AL CLIENTE}

El cliente es el árbitro final de la calidad del producto y del servicio, así como de la fidelidad del cliente. El mejor modo de optimizar la fidelidad y retención del cliente y el incremento de la cuota de mercado es mediante una orientación clara hacia las necesidades de los clientes actuales y potenciales.

\section{LIDERAZGO Y COHERENCIA EN LOS OBJETIVOS}

El comportamiento de los líderes de una organización suscita en ella claridad y unidad en los objetivos, así como un entorno que permite a la organización y las personas que la integran alcanzar la excelencia.

\section{GESTIÓN PROCESOS Y HECHOS}

Las organización actúan de manera más efectiva cuando todas sus actividades interrelacionadas se comprenden y gestionan de manera sistemática, y las decisiones relativas a las operaciones en vigor y las mejoras planificadas se

\footnotetext{
${ }^{31}$ Gestión de la Calidad de los Procesos turísticos Mar Alonso Almeida , Lucia Barcos Rendín , Juan Ignacio Martín Castilla , pag. 222
} 
adoptan a partir de información fiable que incluye las percepciones de todos sus grupos de interés.

\section{DESARROLLO E IMPLICACIÓN DE LAS PERSONAS}

El potencial de cada una de las personas de la organización aflora mejor porque existen valores compartidos y una cultura de confianza y asunción de responsabilidades que fomentan la implicación de todos.

\section{APRENDIZAJE, INNOVACIÓN Y MEJORA CONTINUOS}

Las organizaciones alcanzan su máximo rendimiento cuando gestionan y comparten su conocimiento dentro de una cultura general de aprendizaje, innovación y mejora continuos.

\section{DESARROLLO DE ALIANZAS}

La organización trabaja de un modo más efectivo cuando establece con sus parteners unas relaciones mutuamente beneficiosas basadas en la confianza, en compartir el conocimiento y en la integración.

\section{RESPONSABILIDAD SOCIAL}

El mejor modo de servir a los intereses a largo plazo de la organización y las personas que la integran es adoptar un enfoque ético, superando las expectativas y la normativa de la comunidad en su conjunto.

El Modelo EFQM de Excelencia es un marco de trabajo no - prescriptivo que tiene nueve criterios. Cinco de ellos son "Agentes Facilitadores" y cuatro son "Facilitadores".

\section{Q DE CALIDAD TURISTICA}

Es un distintivo que consiguen aquellos establecimientos que cumplen unos requisitos y estándares que garantizan a los clientes la excelencia en el servicio. La Q supone un distintivo de prestigio, fiable y riguroso, para obtenerla, los 
establecimientos deben someterse de forma voluntaria a unas rigurosas auditorías realizadas por empresas independientes y de reconocido prestigio internacional.

La Q de Calidad hotelera cuenta con el reconocimiento tanto de la Secretaría General de Turismo como de los principales Tour Operadores y Agentes de Viaje, pues forman parte del jurado que la otorga. El organismo certificador de la Q de Calidad Turística es el ICTE (Instituto de Calidad Turístico Español

FUENTE: http://www.gestion-calidad.com/modelo-efqm.html

\section{¿Tienen calidad los hoteles de Buenos Aires?}

Los hoteles de la Ciudad de Buenos Aires tienen poca calidad en cuanto a la denominación "hotel " se refiere pues si existe pues resto son denominaciones extra hoteleras como cabañas, hostel, y bed \&breakfast.

El Programa Buenas Prácticas en Hotelería ${ }^{32}$ (PBPH) se inició en abril de 2003 como un programa piloto aplicado a la localidad de Termas de Río Hondo, Provincia de Santiago del Estero.

Consistió en el otorgamiento de recomendaciones de Buenas Prácticas ambientales a 6 establecimientos hoteleros, a los que se les brindó capacitación dirigida a los gerentes y empleados en la implementación de las mismas, entre otras actividades.

A partir de septiembre de 2003, el PBPH se extendió a otros destinos turísticos, continuando con su implementación en la localidad de San Martín de los Andes, Provincia de Neuquén, ampliándose tanto en su alcance a 10 establecimientos hoteleros y una agencia de viajes, como en el equipo de consultores, a través de los cuales se introdujeron adecuaciones a las características del nuevo destino.

${ }^{32}$ Secretaria de Turismo de San Martín de los Andes.- 
Con posterioridad, el PBPH se desarrolló también en Puerto Madryn, Provincia de Chubut, con la participación de 6 establecimientos hoteleros.

Objetivos y Fases

\section{Objetivos Generales del PBPH}

- Contribuir al logro de un desarrollo sustentable de la actividad turística mediante la implementación de instrumentos novedosos para la gestión de la calidad ambiental, en este caso, a través de la adopción de Buenas Prácticas en Empresas del sector turístico;

- Establecer los lineamientos de un plan de acción para que los establecimientos hoteleros puedan operar bajo la Norma ISO 14.001;

- Fortalecer la cooperación institucional entre la Secretaría de Ambiente y Desarrollo Sustentable (SAyDS) y los diferentes niveles de gobierno y, al mismo tiempo, generar vínculos de colaboración entre el sector público y privado;

- Concientizar a los actores involucrados en el sector sobre la necesidad de desarrollar sus actividades en forma sustentable, incorporando prácticas ambientales.

\section{Fases del PBPH}

Se tomaron las fases que San Martín de Los Andes presentó en su material para trabajar con la Hotelería del lugar 


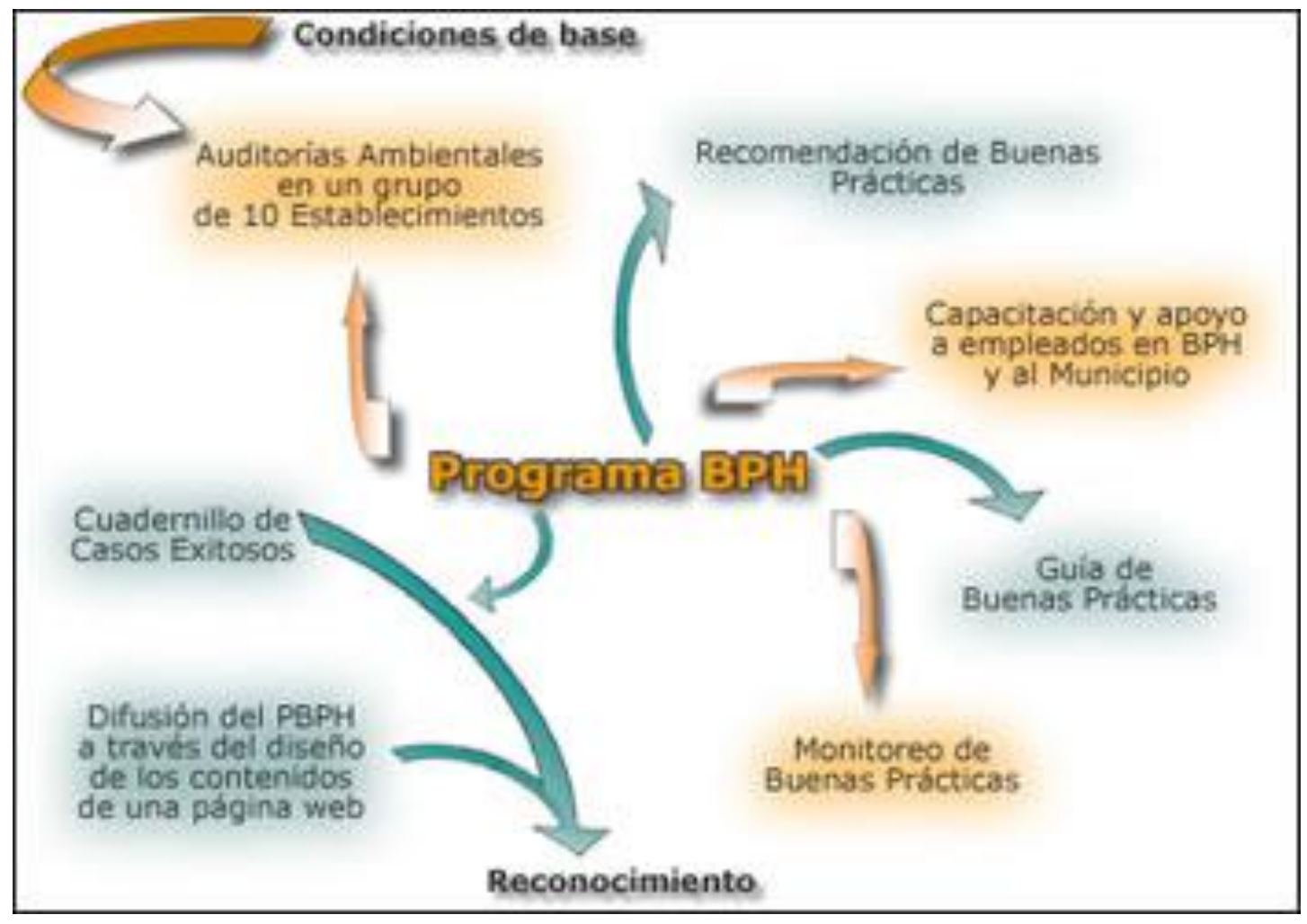

Fuente: Secretaria de Turismo de San Martín de los Andes.-

\section{Beneficios para la Hotelería}

Se pretendió que los establecimientos que adoptaran el PBPH obtuvieran algunos de los siguientes beneficios:

- Asesoramiento gratuito en la implementación de un Programa innovador;

- Mejoramiento de la calidad ambiental dentro del establecimiento y en su entorno;

- Motivación y capacitación complementaria a todos los recursos humanos de los establecimientos, para que de este modo tuviese además un efecto beneficioso en la calidad del servicio;

- Diferenciación de los establecimientos que adoptaron el PBPH en Necochea respecto a los hoteles de otros sitios turísticos;

- Mejoramiento la imagen del hotel dentro de la comunidad, a nivel regional y nacional;

- Presentación de nuevas oportunidades para marketing y promoción del destino; 
- Aumento de la rentabilidad a través de la implementación de medidas de ahorro en consumos de energía, agua y generación de residuos y por la mejoras en las operaciones habituales que son llevadas a cabo por los empleados del establecimiento.

Las Buenas Prácticas que fueron recomendadas a los establecimientos, son medidas muy sencillas orientadas a la conservación del agua, la energía y la reducción de los residuos.

La mayoría de las mismas se pueden aplicar, tanto durante la estadía del huésped en los alojamientos y en los lugares que visitan, como en su vida cotidiana.

Algunas de ellas se exponen a continuación.

1. Programa de Concientización y Sensibilización al Personal y a los Huéspedes (PCSA).

El PCSA es el Programa marco del PBPH y tiene como objetivo comunicar al personal y a los huéspedes, a través de diversos medios y herramientas, las acciones y políticas que el establecimiento ha adoptado para el cuidado del ambiente. Entre ellas, la adhesión al mismo PBPH, los Programas adoptados y las Buenas Prácticas implementadas y todas aquellas medidas que promuevan el turismo responsable en la localidad.

2. Programa de Re uso de Toallas (PRT)

Como su nombre lo indica, el PRT tiene como objetivo lograr la reutilización de las toallas por parte del huésped que lo desee, y de este modo, evitar el lavado innecesario de las mismas. Entre los beneficios ambientales de este Programa se encuentran:

- El ahorro de agua potable,

- La disminución del consumo de energía eléctrica, 
- La menor utilización de productos químicos y por ende reducción de efluentes

- Y la prolongación de la vida útil de las prendas, entre otros aspectos.

\section{Programa de Gestión de Residuos (PGR)}

El PGR tiene como objetivo reducir la generación de residuos sólidos, los cuales son enviados al relleno sanitario de la localidad.

Este Programa y el material utilizado se enfocaron en las tres "R", a saber:

- La reducción de generación de residuos en origen,

- La reutilización de materiales y

- El reciclado.

En este aspecto se trabajará conjuntamente con los programas del PET y del Biodisel

\section{Programa de Mantenimiento Preventivo de Energía y Agua (PMP-AyE)}

El objetivo de este Programa fue detectar las pérdidas en grifos y cañerías en todo el alojamiento, prevenir problemas eléctricos y de gas, y corregir a la brevedad, cualquier anomalía en las instalaciones que pudieran significar un derroche de recursos o significaran un riesgo de accidentes.

\section{Programa de Prevención y Combate De Incendios (PPCI)}

El PPCI tuvo como objetivo iniciar acciones para prevenir y combatir los incendios, ya que resulta imprescindible proteger las vidas humanas tanto de los huéspedes como del personal, al igual que la fuente de trabajo.

La aplicación del Programa permitió: disminuir el riesgo de ocurrencia de incendios en el establecimiento, brindar seguridad al huésped y al personal con relación a la ocurrencia de siniestros, contar con personal instruido para actuar correctamente en caso de incendios y asegurar la existencia de los equipos en condiciones para el de combate de incendios. 


\section{Buenas Prácticas Adicionales (BPA)}

Las Buenas Prácticas Adicionales tiene como objetivo optimizar y colaborar con los objetivos ambientales globales de ahorro de agua, energía y minimización de residuos planteados oportunamente en los Programas antes descritos, de modo que pudiesen servir de apoyo y mejora de los mismos.

Algunas de las medidas recomendadas son las siguientes:

- Reemplazar las lámparas incandescentes por lámparas bajo consumo;

- Efectuar el monitoreo mensual de los consumos de agua y energía;

- Establecer una Política de compras para el establecimiento y utilizar especies autóctonas en parques y jardines, entre otras.

\section{Mejoras Tecnológicas}

Los Programas y Buenas Prácticas Adicionales presentadas anteriormente pueden ubicarse dentro de la categoría de medidas que se focalizan en la prevención, planificación y en cambios de hábitos del personal y de los huéspedes en cuanto a la utilización racional de recursos.

Existen otras medidas que pueden ubicarse dentro de una segunda categoría, constituida por aquellas de orden técnico, las cuales implican la incorporación o modificaciones de dispositivos, equipos, instalaciones, etc. en el alojamiento.

Las Mejoras Tecnológicas (MT) requieren para su implementación una considerable inversión económica, siendo ésta una condición que se encuentra fuera de los objetivos principales estipulados en el PBPH.

Igualmente, el Equipo Consultor encargado de llevar adelante el Programa las otorgó a título informativo, para que se pudiesen tener en cuenta en futuras ampliaciones, remodelaciones y/o construcción de nuevas unidades o habitaciones.

Los siguientes ejemplos son algunas de las mejoras tecnológicas recomendadas:

- La colocación de grifos con aireador; 
- Con temporizador y con censor infrarrojo;

- La instalación de sanitarios eficientes o la colocación de llaves con tarjetas en las habitaciones, entre otras medidas.

\section{La Gestión Integral de los Residuos}

El programa de gestión de residuos plantea la participación del turista en la Separación de Residuos dentro de la unidad de alojamiento, tanto en cabañas como en las habitaciones de los hoteles y hosterías.

Los residuos no degradables como Botellas plásticas y de vidrio, son clasificados y depositadas en recipientes específicos, que luego son acopiados en sitios especiales en el establecimiento.

A solicitud del grupo de alojamientos, la Municipalidad a través del cuerpo de Guardas Ambientales, realiza una recolección especial una vez a la semana de estos residuos que son depositados en un predio diferente al Relleno Sanitario de la ciudad, previendo su reutilización posterior en distintas aplicaciones: para plantines del Vivero Municipal, para la realización de Invernaderos, etc.

Esta tarea se inició en forma paulatina ya comenzada la temporada invernal.

Los resultados obtenidos en ese periodo son los que se expresan en el siguiente gráfico. 
Recolección diferenciada de Residuos (temporada Invernal 2004)

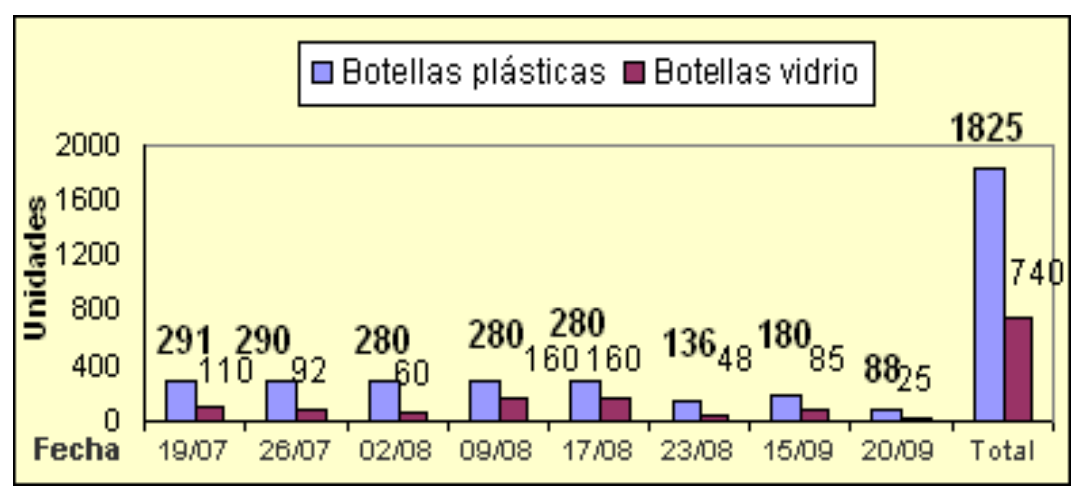

Fuente: Recolección de datos Guardas Ambientales. Procesamiento Sec. De Turismo. Municipalidad de San Martín de los Andes

La receptividad de los turistas ante la propuesta de participar con prácticas ambientales durante su estadía es monitoreada en forma individual por parte de cada establecimiento, mediante una encuesta que es utilizada por todos los establecimientos en forma conjunta, cuyos resultados son procesados periódicamente por la Secretaría de Turismo Municipal.

\section{Buenas prácticas adoptadas por los turistas en alojamientos}

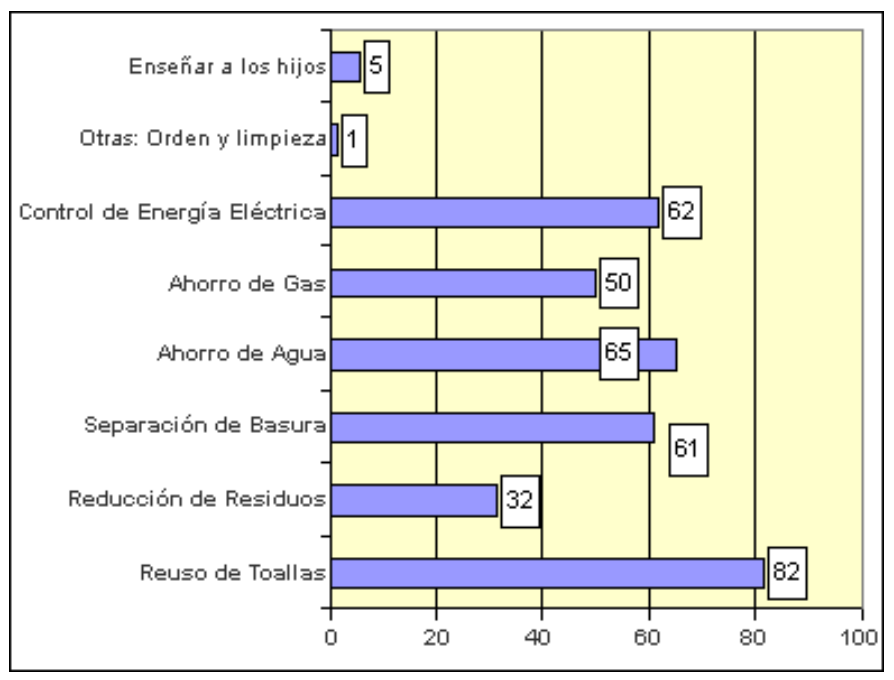


Fuente: Recolección de datos Alojamientos del Programa. Procesamiento Sec. De Turismo. Municipalidad de San Martín de los Andes. Valores expresados en porcentaje.

\section{Prácticas Adoptadas en los Paseos}

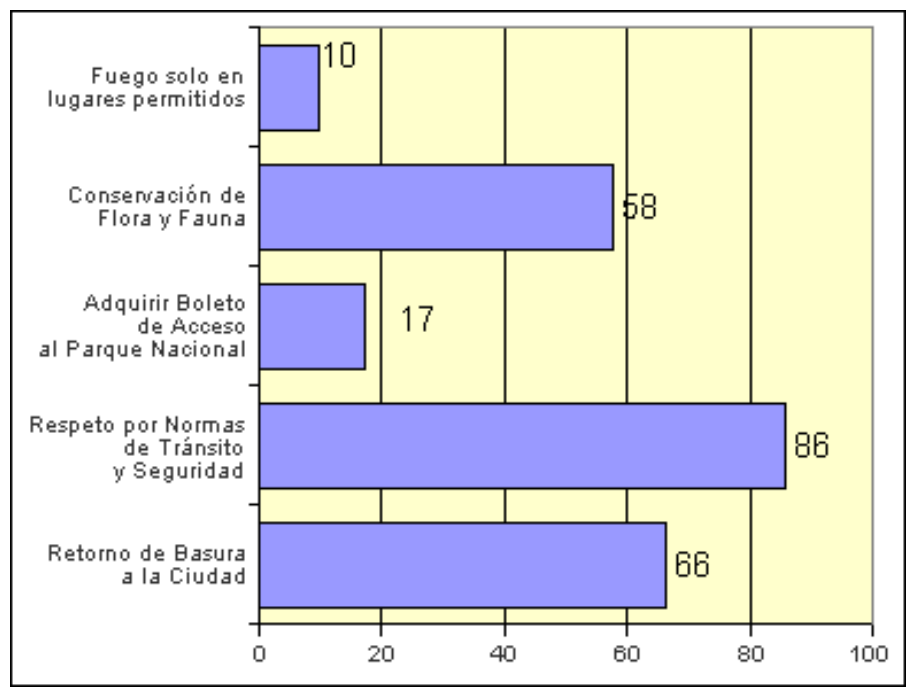

Fuente: Recolección de datos Alojamientos del Programa. Procesamiento Sec. De Turismo. Municipalidad de San Martín de los Andes. Valores expresados en porcentaje.

Indudablemente se cuenta con una amplia aceptación de los huéspedes hacia las iniciativas de los alojamientos, participando activamente con buenas prácticas tanto dentro del alojamiento como en sus paseos por la ciudad y el parque nacional, que se intensificaran sin lugar a dudas durante la temporada estival.

La satisfacción respecto al ambiente en la localidad es del 78\% Satisfactorio y Muy Satisfactorio.

La calidad de la información recibida en el establecimiento es del 84\% Excelente y Muy buena. 


\section{Opiniones sobre las Acciones}

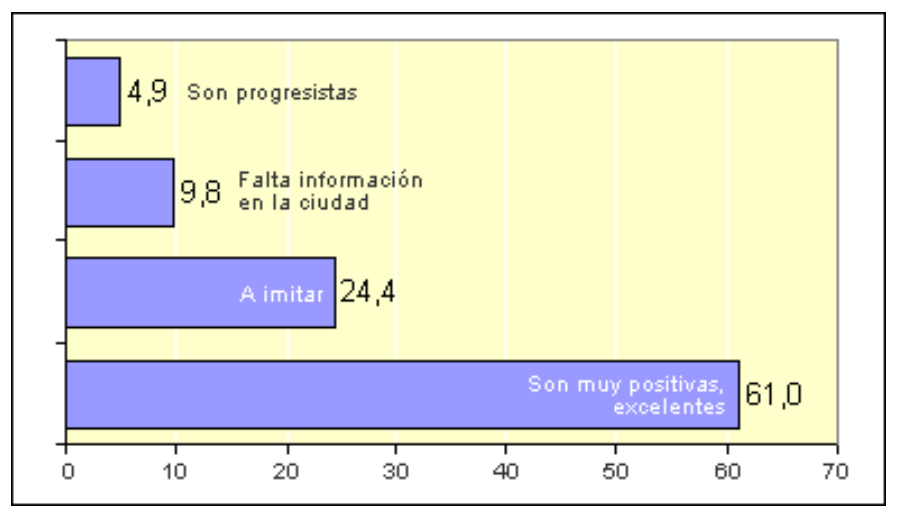

Fuente: Recolección de datos Alojamientos del Programa. Procesamiento Sec. De Turismo. Municipalidad de San Martín de los Andes.

Respondiendo la pregunta hecha si los hoteles de Buenos Aires tienen calidad y consultando al Ministerio de Turismo de la Nación son muy pocos los hoteles de la ciudad de Buenos Aires que tienen calidad. La mayoría de los establecimientos hoteleros se encuentran en la Provincia de Buenos Aires y la mayoría son establecimientos extra hoteleros no contemplados en la legislación hotelera nacional.

La cultura de la calidad que es necesaria para una mayor competitividad y también para una mayor calidad en el servicio y satisfacción al cliente y también que contribuyan a la creación de empleo capacitado y oferta calificada, facilitando el desarrollo económico. 


\section{Capítulo IV}

\section{Propuesta final}

\section{Proyecto de Ley Nacional de Hotelería}

\section{Introducción}

El Ministro de Turismo de la Nación ha dicho "La actual gestión de gobierno que lidero, entiende al Turismo como Política de Estado. Así ha quedado establecido en la Ley Nacional de Turismo, herramienta madre capaz de guiar las actuaciones que se realicen en pos del desarrollo de este sector". 33

Este desarrollo turístico es entendido como un proceso progresivo y gradual en el que habrán de integrarse objetivos de equidad social, sustentabilidad ambiental y eficiencia económica, que permite visualizar al turismo como una actividad económica capaz de constituirse en un motor fundamental de la Economía Nacional, dada su capacidad de generar un efecto multiplicador en el empleo y la producción.

En este sentido, la gestión de la calidad se ha convertido en un elemento vital que permite a los actores del sistema turístico argentino orientar sus procesos de gestión hacia la cultura de la mejora continua y asegurar, de esta forma, un desarrollo sustentable basado en criterios de responsabilidad social, ambiental Dr. Meyer Ministro de Turismo de Nación”.

\footnotetext{
${ }^{33}$ Ministerio de Turismo de la Nación www.turismo.gov.ar
} 
El turismo, esa compleja actividad que ha ido cambiando acorde al desarrollo general del capitalismo hasta transformarse hoy, en la era de la globalización, en uno de sus pilares económicos e ideológicos requiere ser abordado para su estudio desde múltiples ángulos y diversas disciplinas. Esta actividad se ha transformado en un corto tiempo en una de las más importantes fuentes de riqueza de los países donde se desarrolla que son, en primer lugar, los con mayor desarrollo económico y luego, en los países de la periferia, lo que la ha llevado a ubicarse entre las primeras actividades

El turismo es un factor realmente importante para el desarrollo socioeconómico y cultural de un país, dada la diversidad de actividades favorables que traen bonanzas económicas: es un instrumento generador de divisas, al ser una actividad que canaliza una inversión para producir una expansión económica general; genera asimismo un mercado de empleos diversificado con una inversión relativamente baja en comparación con otros sectores de la economía; genera una balanza de pagos favorables y sobre todo desarrolla las actividades económicas locales.

El Turismo es un medio de intercambio social, ya que muestra efectivamente que la sociedad que desarrolla más activada se capacita hacia la comprensión, para la adaptación de sus medios habituales, juzgando de una manera positiva su propia sociedad.

En cuando a la cultura es realmente el radio dentro del campo de la acción de la empresa turística. Cultura es el término que determina el imán que poseen las regiones para el turismo comprendiendo su geografía, historia, costumbres, tradiciones, folklore y artesanía.

Generalizando el Turismo es la industria del futuro de todos aquellos países en vías de desarrollo que sepan aprovechar al máximo todos sus recursos. 
El Ministro de Turismo Carlos Enrique Meyer expresó que es el objetivo es garantizar la comprensión de los beneficios de gestionar calidad integralmente sobre la base de distintos factores como la seguridad, la preservación de la identidad cultural y del ambiente natural y la accesibilidad, entre otros, este último concepto el de accesibilidad también es unos de los principios rectores de la Ley Nacional de Turismo y nos indica la opción de promover la eliminación de todas las barreras que impiden el uso y goce del turismo a todos sus visitantes

Las normas constituyen herramientas para que una organización pueda mejorar la calidad de sus productos o servicios , permitiéndole mantener así como actualizar, los estándares alcanzados a lo largo del tiempo, de forma tal de obtener la constante satisfacción de las necesidades del cliente e incluso superar las expectativas de este.

Una norma es un documento ordenador de una cierta actividad que contiene especificaciones técnicas extraídas de la experiencia y de los avances de la tecnología.

Entre las normas de mayor aplicación se encuentran la norma ISO series "la mejora cuantitativa de la oferta turística de alojamientos constituye una línea prioritaria de actuación política "del Gobierno Nacional que tiene que realizarse con decidido impulso institucional pero también con el concurso del sector turístico privado".

Esta norma viene a dar seguridad jurídica al campo del sector hotelero para una aplicación correcta e integrada de la normativa exigible a los alojamientos hoteleros y extra hoteleros, objetivo principal de esta Ley permite conseguir básicamente los objetivos de modernización y actualización del mismo. 


\section{Proyecto de ley nacional de hotelería}

\section{Capítulo preliminar}

Objeto, ámbito de aplicación, principios rectores y sujetos de aplicación

Art. 1: Objeto y Ámbito de aplicación

La presente ley regula la prestación del alojamiento turístico en todo el territorio la Nación Argentina y los recaudos para la clasificación, categorización, inscripción y control de los establecimientos en los que se brinda.

Todos los establecimientos de alojamiento turísticos hoteleros y extra hoteleros existentes en la República Argentina cuya solicitud de construcción o de apertura haya tenido lugar antes de la sanción de esta ley deberán superar la inspección técnica del plan de modernización que se crea y que se regula por esta ley.(tomado de la ley de hotelería de la legislación de las Islas Baleares) autor Dr. Avelino Blasco

Art. 2:

Créase por medio de la presente Ley de Hotelería Nacional con principios de calidad turística el Consejo de Calidad Turística Nacional como autoridad de aplicación y el Plan de Modernización para los emprendimientos hoteleros y extra hoteleros.-

Art. 3: Principios Rectores

Constituyen sus principios rectores en forma complementaria a los siguientes principios:

1. Promover la calidad turística hotelera y extra hotelera en la diversidad de la oferta de alojamientos turísticos.- 
2. Propender a la excelencia del servicio de alojamiento turístico, acorde a la realidad del mercado, de manera de favorecer la sana competencia entre los establecimientos.

3. Tender a toda eliminación de barreras físicas que impidan el uso y goce de los servicios brindado por los alojamientos turísticos según las directrices de alojamientos turísticos propuestos el Ministerio de Turismo de la Nación Argentina.-

Art. 4: definiciones:

A los fines de esta ley se entiende por servicio de alojamiento turístico, aquel que se presta en establecimientos de uso público, en forma habitual o temporaria, por una tarifa determinada y un periodo no menores al pernocte, al que pueden sumarse otros servicio complementarios, siempre que las personas alojadas no constituyan domicilio permanente en ellos se clasificará como:

Hotel: Es aquel alojamiento hotelero que presta al turista, mediante contrato de hospedaje, los servicios de gastronomía, recepción, portería y personal de servicio sin perjuicio de los demás que para cada categoría se indiquen.

Apart Hotel: Son aquellos establecimientos que prestan al turista o usuario el servicio de alojamiento en edificios de departamentos que integran una unidad con administración común ofreciendo además los servicios propios del hotel.-

Hostel: Establecimiento que brinda alojamiento no permanente inferior a 30 plazas conformado por habitaciones compartidas y/o por habitaciones privadas (singles) dobles o triples o cuádruples con o sin baño privado. Cuenta con sala de estar y cocina de uso común.-

Casa de huéspedes (bed and breakfast): Servicio de alojamiento turístico de tipo familiar con desayuno que brinda en establecimientos que no han sido diseñados específicamente para este uso.-

Hoteles Boutique: Son hoteles pequeños, con poca cantidad de habitaciones y atención personalizada. Algunos son edificios antiguos con características 
arquitectónicas relevantes, restaurados en todo su esplendor. Algunos de ellos suelen ser temáticos.

Bungalows: Son unidades independientes con capacidad entre 4 y 8 personas; constan de uno o dos dormitorios, sala, comedor, cocina y baño. Suelen estar enmarcadas en un contexto natural y poseen entrada de vehículos.

Lodge: Es un establecimiento pequeño, construido en un entorno rural y en armonía con el mismo. Su edificación es en base a elementos propios del ambiente donde está emplazado.

Campings: Modalidad de alojamiento, donde no se presta ningún servicio de alojamiento. Consiste en la acotación y parcelación de un terreno para uso privativo mediante la instalación de su propio sistema de alojamiento. Se facilita el uso de instalaciones como los sanitarios, los espacios para lavar y tender la ropa, piscinas, salones de juegos, etc. Deben reunir una serie de garantías de calidad y habrán de registrarse como empresas turísticas para ser considerados turísticos.

Moteles: Establecimiento que brinda servicio de alojamiento en habitaciones individuales con baño privado, con acceso independiente a las habitaciones, contando con estacionamiento vehicular ubicado junto a cada unidad y en cantidad igual al número de unidades, en el cual se preste el servicio de alojamiento con servicios complementarios.

Hostería: Establecimiento que brinda servicio de alojamiento en habitaciones individuales con baño privado, departamentos y suites, con una capacidad mínima de 5 unidades, en el cual se preste el servicio de alojamiento y otros servicios complementarios, según los requisitos indicados para cada categoría, y que por sus características no puede ser encuadrado en la clase hotel.

Residencial: Establecimiento que brinda servicio de alojamiento en habitaciones individuales con baño privado, con una capacidad de 5 habitaciones, en el que se preste el servicio de alojamiento con o sin servicios complementarios, según los requisitos establecidos para cada categoría, y que por sus condiciones arquitectónicas y de servicios no puede ser encuadrado en las clases anteriores. 
Albergue: Establecimiento que brinda servicio de alojamiento grupal. Dedicado al alojamiento de contingentes y/o grupos de personas, con baños comunes o privados, que cuenten con condiciones mínimas de habitabilidad fijadas por la autoridad de regulación edilicia y de servicios turísticos.

Apart Cabañas: Unidades de alojamiento independientes y aisladas entre sí, que formando conjunto con otras, con un mínimo de 3, brinden servicios de alojamiento, con servicios complementarios, contando como mínimo áreas de dormitorio, baño, cocina y estar comedor, debidamente equipados. Conforme lo establecido en la presente reglamentación para cada clase y categoría. El servicio de alojamiento deberá contratarse por unidad.

Conjunto de casas y departamentos: Unidades de alojamiento independientes, que agrupadas, y formando conjunto con otras, con un mínimo de 3 , brinden servicio de alojamiento, contando como mínimo con áreas de dormitorio, baño, cocina y estar comedor debidamente equipados.

Complejo turístico: Establecimiento que presta servicio de alojamiento en una o más de una clase reconocida por la presente reglamentación, sujeta en cada caso a las condiciones que rigen para cada clase, contando con servicios complementarios, y con superficies afectadas al desarrollo de actividades turísticas, deportivas, recreativas, en cantidad y diversidad de acuerdo a lo que establezca cada categoría la presente reglamentación.

Complejo especializado: Establecimiento que presta servicio de alojamiento en una o más de una clase reconocida por la presente, integrado a la prestación de un servicio especializado y ajeno al alojamiento, y/o que por su localización rural se encuadre en la presente clase. En todos los casos, deberán compatibilizarse, adecuarse y ajustarse a las características del servicio de alojamiento, a los requerimientos y necesidades especiales y particulares de los servicios especializados que se prestan.

Clasificaciones:

Hotel

Hostel

Motel

Hosteria 
Cabañas, Bungalows

Bed and breakfast o casa de huéspedes

Apart hotel

Residencial

Casas y Departamentos

Complejo Turistico

Lodge

Complejo Especializado

Quedan excluidos los albergues transitorios

\section{Capítulo I}

\section{Conformación del sector de alojamiento turístico \\ Plan de modernización}

Art. 5:

Para construir un nuevo establecimiento hotelero o de alojamientos turísticos será necesaria la autorización (legislación turística de Islas Baleares, España) de la autoridad de aplicación que será Consejo Consultivo de Calidad Hotelera de la Nación. La organización hotelera como lo dispone la ISO 9000:2000 debe establecer, documentar, implementar y mantener un sistema de gestión de calidad y mejorar continuamente su eficacia de acuerdo con los requisitos de esta norma internacional.

La organización hotelera deberá:

- Identificar los procesos para el sistema de gestión de calidad y mejorar continuamente;

- Determinar la secuencia e interacción de estos procesos;

- Determinar los criterios y métodos necesarios para asegurarse de que tanto la operación como el control de estos procesos sean eficaces; 
- Asegurarse de la disponibilidad de recursos e información necesarios para apoyar la operación y el seguimiento de estos procesos;

- Realizar el seguimiento, la medición y el análisis de estos procesos;

- Implementar las acciones necesarias para alcanzar los resultados planificados y la mejora continua de estos procesos.

Art. 6:

Todos los alojamientos hoteleros y extra hoteleros nuevos a partir de esta ley de hotelera deben superar la inspección técnica a partir de la vigencia de misma. Esta inspección técnica es acorde al plan de modernización que se crea con la misma y se regula por medio de la presente ley.-

Art. 7:

El Plan de inspecciones de los establecimientos afectados por la presente Ley se realizara de acuerdo a las siguientes prioridades.

En primer término Se inspeccionaran aquellos establecimientos que hayan sido objeto de reiteradas reclamaciones sobre instalaciones y equipamientos.

En segundo término Se procederá a la inspección de aquellos establecimientos que con carácter voluntario lo soliciten.

En tercer término y por orden cronológico de la fecha de apertura el resto de los establecimientos afectados.-

Art. 8:

La inspección técnica se realizara mediante visita detallada de cada establecimiento. Si se comprueba la adecuación del establecimiento a las previsiones de esta Ley se considera superada y el Consejo de Calidad turística hotelera previo los tramites dictara resolución acreditando que el establecimiento se adecua a las prescripciones de la presente Ley.-

Art. 9: 
Si no se ha superado la inspección técnica y una vez que el de la curso de la misma se hayan determinado las obras y mejoras a realizar en cada establecimiento habiendo ponderado su importancia e intensidad de acuerdo a la presente ley.-

Art. 10:

Para construir una nuevo un establecimiento hotelero y alojamiento turístico o para su ampliación o para un cambio de uso de edificación con finalización de utilización turística, será necesaria una superficie en $\mathrm{m} 2$ de suelo edificable no inferior al resultado de multiplicar por 70 el máximo número de plazas que pueda albergar este establecimiento. Este suelo quedara exclusivamente afectado por el uso turístico que se pretende no podrá albergar otras instalaciones o construcciones que no estén estrictamente ligadas a la explotación turística.-

Art. 11:

Los establecimientos hoteleros obsoletos que adquieran el compromiso de darse de baja turística con posterior demolición del inmueble podrán ser sustituidos por nuevos hoteles.-

\section{Capítulo II}

\section{Titulares de establecimientos de alojamientos turísticos}

\section{Art 12: Deberes}

Sin perjuicio de los establecidos de la Ley Nacional de Turismo y aquellos que establezcan las normas reglamentarias y complementarias los siguientes:

1. Contar con la autorización otorgada por la Autoridad de Aplicación y encontrándose inscriptos en el Registro de Prestadores Turísticos .

2. Exhibir en lugar visible del frente externo del establecimiento una placa identificadora donde se lea la clase, la categoría. 
3. Indicar clara y legible toda su papelería comercial.

4. Mantener el establecimiento en optimas condiciones de higiene, seguridad y conservación y brindar a los huéspedes las comodidades y servicios mínimos que correspondan a cada clase.

5. Respetar la normativa del Código de Urbanización.

6. Garantizar a los huéspedes seguridad las 24 hs.

7. Disponer de asistencia médica de urgencias y botiquín de primero auxilios equipado en relación directa a la capacidad de las plazas del hotel.

8. Promover al huésped información clara y veraz y visible sobre los servicios ofrecidos, condiciones que prestan, políticas de calidad .La información debe brindarse en castellano, inglés y portugués como mínimo. Se deberá exhibir tarifario para servicios adicionales.

9. Comunicar a la Autoridad de Aplicación toda modificación de la estructura edilicia, de los servicios o de cualquiera en las que fue obtenida la autorización.

10. Notificar la transferencia venta o cesión del establecimiento dentro de los cinco de producida.

11. Disponer de un sistema de reservas.

12. Contar con un libro de conformidades y no conformidades, foliado y rubricado por la Autoridad de Aplicación.

13. Llevar reportes estadísticos.

14. Respetar la normativa medio ambiental.

15. El personal deberá tener conocimiento de idiomas.

16. El personal cuida su imagen frente al cliente.

17. Respetar la capacidad máxima de plazas autorizadas para cada unidad de alojamiento, evitando el overbooking. Dicha capacidad deberá ser aprobada por el expreso consentimiento del huésped por escrito.

18. Tener en cada habitación el reglamento del establecimiento.

19. Exhibir de forma clara y legible el valor de moneda nacional y su equivalente en moneda extranjera. 
20. La dirección deberá asumir la responsabilidad del servicio ofrecido en el hotel aportando las instalaciones equipamiento y recursos y herramientas de gestión necesarias para asegurar que se cumplan los procesos del servicio y los objetivos de la calidad, seguridad y ambiental en forma sustentable.

Art .13: Derechos

1. Formar parte del Registro de Prestadores Turísticos Nacional y ser incluidos en catálogos, directorios, sistemas informáticos y toda gestión de promoción y difusión.

2. Contar con asistencia, información y asesoramiento del personal técnico de la Autoridad de Aplicación.

3. Rescindir el contrato de hospedaje y proceder al desalojo a los huéspedes que se nieguen a abonar la cuenta a la fecha establecida y tomar todos los recaudos para cobrar la cuenta.

4. Ejercer el derecho de retención.

\section{Capítulo III}

\section{Del ordenamiento}

Art.14:

Los alojamientos turísticos se ordenaran por la siguiente tipificación:

De playa Aquellos establecimientos que además de su ubicación inmediata a las orillas del mar, lagos lagunas o ríos estén orientados al aprovechamientos de alguno de estos atractivos turísticos Constituyen un complemento al desarrollo de actividades de descanso contacto con la naturaleza pesca y demás deportes náuticos. 
De montaña Aquellos establecimientos que por su ubicación en la pre cordillera o alta montaña estén orientados al aprovechamiento de sus atractivos. Constituyen tales como andinismo, excursionismo y otros deportes.

Del campo aquellos establecimientos que por su ubicación en zonas des escasa densidad demográfica u aéreas ruarles, estén orientados al aprovechamiento de esos atractivos turísticos en dichas zonas. Constituyen como realizaciones culturales, comerciales, científicas sociales y recreativas.

Termales Aquellos establecimientos que están ubicados en el perímetro de una fuente o centro de aguas termales.

Por su estacionalidad

Anuales

De Temporada

\section{Capítulo IV}

\section{Del ordenamiento y equipamiento}

Art. 15:

El establecimiento debe ser un espacio agradable y atractivo para el cliente.

Art 16:

Disponer de un espacio de recepción amplio y confortable.

\section{Art 17:}

En las habitaciones de servicios que proporciones la información necesaria para la comodidad y satisfacción del cliente. 
Art 18:

Se ha de facilitar la realización por parte del cliente de quejas y sugerencias, se debe indicar al cliente de forma visible y clara que el establecimiento pone a su disposición la recogida de quejas o sugerencias.

Art.19:

El establecimiento dispone de modelos de encuestas o entrevistas. El establecimiento debe disponer de unos modelos de encuestas o entrevistas personales a clientes acerca del servicio recibido y del nivel de satisfacción alcanzado durante su estancia en el establecimiento.

\section{Capitulo V}

\section{Consejo de calidad hotelera turística}

Art. 20:

Crease el Consejo de Calidad Hotelera Turística conformado en el ámbito del Consejo de Calidad Turística Nacional creado por la presente ley.-

El consejo se integra por dos representantes del Ministerio de Turismo de la Nación uno de los cuales debe ocupar la Presidencia con voz y voto doble en caso de empate y dos representantes del sector privado vinculado a la actividad hotelera.-

\section{Art 21:}

Sus funciones son: Proponer modificaciones para la clasificación y categoría y modalidades de los establecimientos de alojamientos turísticos y proponer las medidas conducentes a una mejor calidad en el servicio de la actividad. Asesorar en la incorporación en nuevas clases de alojamientos y sus requisitos.-

\section{Capítulo VI}

\section{Disposiciones transitorias}


Art 22:

Los establecimientos que soliciten su inscripción desde la publicación de la presente y hasta tanto se encuentre reglamentada deberán inscribirse en el Registro especial que la Autoridad de Aplicación establezca al efecto.-

\section{Disposiciones finales}

ART 23:

DEROGUESE LA LEY 18828 Y SU DECRETO REGLAMENTARIO

Art 24:

La presente ley entra en vigencia a partir del día de su publicación en el Boletín Oficial.- 


\section{Conclusiones}

La calidad se refiere a la totalidad de los ámbitos y actividades en los que opera la organización, es preciso un enfoque proactivo que incluya una visión clara de a donde se quiere dirigir la organización así como una estrategia definida y un liderazgo coherente con dicha visión y estrategia.

La cultura de la calidad ha de enraizarse en el sector hotelero para una mayor competitividad y una mayor satisfacción al cliente como asi también la mayor satisfacción al cliente y una mejora en la oferta y una mejor calidad en los empleos.

La inclusión de los principios de calidad en una norma obligatoria no es nada descabellado toda vez que el Dr. Eugenio del Busto en su exposición en el 1er Congreso Iberoamericano del Derecho del Turismo ha dicho que " se advierte la relevancia de incorporar parámetros de calidad a las futuras normas que se dicten, ya que a la fecha la categorización de los establecimientos, en un importante números de casos, responde esencialmente a aspectos de índole material ( edilicia en particular) y no a los servicios que se prestan".

Si bien estar certificado bajo las normas de calidad ISO - IRAM SECTUR conlleva un reconocimiento acerca de los estándares de calidad en los servicios, es cierto que aplicar para este tipo de reconocimiento es voluntario y bajo ningún concepto debe verse o sentirse como una obligación.

Este proyecto de Ley debería servir como punto de partida y apoyo para aquellos establecimientos que quieran lograr dicha certificación, de manera que sus actividades estén concebidas bajo aquel marco teórico pero también dentro de la normativa legal vigente. 
La implantación de la cultura de la calidad en el sector hotelero brindara una mayor fidelización de los huéspedes.

El cambio en el escenario turístico internacional que repercute en nuestro país obliga a adaptar la normativa sobre la base de criterios más flexibles, dinámicos y modernos en pos de un crecimiento sostenido y planificado de la actividad turística.

Es por ello que el planteamiento de una norma jurídica que contenga políticas de calidad y también principios de las normas de calidad le dará criterios más flexibles y dinámicos al sector ya que podrán adaptarse con más facilidad y por ende tener una mejora continua redundando en una mayor rentabilidad, creando mayores puestos de trabajo y una mayor fidelización de los huéspedes asimismo se estará cumpliendo con el medio ambiente y con la defensa del consumidor al brindar un servicio de calidad .

La inserción de la cultura de la calidad en la norma jurídica hotelera es una necesidad de estos tiempos para que haya una mejora continua en los servicios que presten los establecimientos hoteleros, no solo esto sino también una garantía en los servicios ofrecidos.

Las normas ISO-IRAM MINTUR son una fuente importante para ser implementadas en la norma jurídica hotelera, como así también el modelo EFQM parra hoteles de 5 estrellas para que certifiquen excelencia en calidad.-

La cultura de la calidad tiene que empezar en cabeza del empresario hotelero pues ahí empieza la mejora continua y de ahí el mejoramiento en los servicios hoteleros.-

Cualquier establecimiento hotelero puede alcanzar la calidad ya sea buenas prácticas como asi también el premio a la excelencia de la calidad. 
La implementación de la calidad en la norma jurídica hace que los hoteles sean sustentables en el tiempo. 


\section{Bibliografía}

BLASCO ESTEVE, Avel li, SEGURA FUSTER, Frances, OLIVER CLARM Pep, (2007) LEGISLACION TURISTICA ED. INSTITUT D ESTUDIS AUTONOMICS- Ed. Govern de les ILes Balears

BOZZANO, Horacio ( 2009) TERRITORIOS POSIBLES , PROCESOS LUGARES Y ACTORES.ED. LUMIERE BUENOS AIRES (2009)

BECH SERRAT, Josep - "NORMAS DE CALIDAD DE LOS SERVICIOS TURÍSTICOS: UNA APROXIMACIÓN DESDE EL DERECHO CONTRACTUAL EUROPEO- Conferencias y Ponencias del 1er Congreso Iberoamericano del Derecho del Turismo-Ediciones Ladevi- Buenos Aires COLECCIÓN DERECHO DEL TURIMO- CONFERENCIAS \&PONENCIAS 1er congreso iberoamericano de Derecho del turismo PP.

CARDOSO,Henrique 1995 a 1999, www.embratur.gov.br/embratur/indur.html Font, X. \& R.C. Buckley;

CASANOVA FERRO, Gonzalo Turismo de Calidad y experiencia Normativa. COLECCIÓN DERECHO DEL TURIMO- CONFERENCIAS \&PONENCIAS 1er congreso iberoamericano de Derecho del turismo PP.

Decreto 659/07 del 16 de Mayo de 2007. Reglamento de Alojamientos turísticos provincia de buenos aires.

DEL BUSTO, Eugenio Marco Regulatorio de la actividad de alojamientos turísticos en la República Argentina COLECCIÓN DERECHO DEL TURIMOCONFERENCIAS \&PONENCIAS 1er congreso iberoamericano de Derecho del turismo PP.

ECOTEL: www.hvsecoservices.com/ECOTELAbout_Criteria.htm.

EMBRATUR, 1999, A indústria do Turismo no Brasil antes e después de Fernando

Green Globe Asia-Pacífico (www.ggasiapacific.com.au/news/docs/IES.pdf) y comunicación personal con Alice Crabtree. 
GESTION DE CALIDAD DE LOS PROCESOS TURISTICOS, EDITORIAL SINTESIS. AUTORES MAR ALONSO ALMEIDA, LUCIA BARCOS RENDIN, JUAN IGNACIO MARTIN CASTILLA

GUTIÉRREZ RODRÍGUEZ José Arnulfo (2006) Propuesta de implantación de la Cultura de la calidad en el hotel Bellavista de Coatzacoalcos Tesis; Facultad de Contaduría y Administración, Coatzacoalcos. Universidad Veracruzana Maestría en gestión de la calidad

IGLESIAS, CRISTINA, CALIDAD DE SERVICIO Y SASTIFACCION AL CLIENTE-UNIVERSIDAD DE QUILMES

NORMA ARGENTINA IRAM SECTUR 42200 HOTELERIA SISTEMA DE GESTION DE CALIDAD, LA SEGURIDAD Y EL AMBIENTTE

LEY NACIONAL DE HOTELERIA 18828

LEY NACICIONAL DE TURISMO

LEY 600 (07/06/2001), LEY DE TURISMO CABA

LEY NRO 8819 LEY DE ALOJAMIENTOS TURISTICOS DE LA PROVINCIA DE LA RIOJA.-

NORMA MARTINEZ Y ADRIANA ROSENFELD,2011 NORMAS DE CALIDAD, RESPONSABILIDAD SOCIAL Y TURISMO: HACIA UN TURISMO SUSTENTABLE-.EDICIONES-LADEVI- COLECCIÓN DERECHO DEL TURISMO:

NORMA ARGENTINA IRAM SECTUR 42220 CASA DE HUESPEDES (bed \& breakfast) Sistema de gestión de calidad la seguridad y el ambiente Requisitos

NORMA ARGENTINA IRAM SECTUR 42210 CABAÑAS SISTEMA DE GESTION DE CALIDAD LA SEGURIDAD Y EL AMBIENTE REQUISITOS NORMA INTERNACIONAL ISO 9001

(OMT), 2002 ECOTRANS, Voluntary Initiatives for Sustainable Tourism: Worldwide inventory and comparative analysis of 104 eco-labels, awards, and self-commitments, Organization Mundial de Turismo

OMT. 2004 The Joint Wto \& Ih\&Ra Study On Hotel Classification. International Hotel \& Restaurant Association - OMT, 
ORDENANZA n ${ }^{\circ}$ 36136/80 Reglamento de Alojamientos Turísticos Ciudad de Buenos Aires

ROERTO BOULLON ,2003,CALIDAD TURISTICAE EN LA PEQUEÑA Y MEDIANA EMPRESA, EDICIONES TURISTICAS, -Buenos Aires

SANTOMÁ, Ricard; Gerard Costa Calidad de servicio en la industria hotelera:

Revisión de la literatura

SECTUR, 2005 Plan Federal de Turismo Sustentable

TOURISM ECOLABELLING (2001): Certification and Promotion of Sustainable Management; CABI Publishing,

DECRETO NRO 1264/80 REGLAMENTACION DE ALOJAMIENTOS TURISTICOS DE LA PROVINCIA DE CHUBUT

REGLAMENTO DE ESTABLECIMIENTOS DE HOSPEDAJE, DECRETO SUPREMO NRO 029-2004 MINCETUR-REPUBLICA DEL PERU.- 


\section{Anexo I: Encuesta al sector hotelero para tesis}

Hotel: Asociación de Hoteles de Turismo de la Rep. Arg.

Localidad: Cap. Fed.

Categoría: Hoteles de 5 y 4 *

Cantidad de habitaciones: Tenemos Hoteles de 5 a 1.000 Habitaciones.

1-La legislación se encuentra: En el año 2004/5 con la nueva ley Nacional de Turismo comenzó un proceso de aggiornamiento de la legislación turística. Esta ley le da un nuevo espacio protagónico al sector privado desde la CAT, haciéndolo al sector privado socio estratégico conjuntamente con el Sector Público de la actividad, lo que se ve materializado en el IMPROTUR.

Esto no quiere decir que se solucionaron todos los problemas, fue un buen comienzo para el desarrollo de una nueva etapa, que siguió con algunas leyes, como la de turismo estudiantil, Corrimiento de los Feriados, etc....

Debería ahora armarse una agenda con la problemática específica del Turismo en general y de la Hotelería en particular, a nivel de los aspectos que potencien y sustenten la competitividad de todo el Turismo y la problemática específica del sector, como son: la Categorización Hotelera a nivel Nacional; La Competencia Desleal; los Departamentos de alquiler; Los Derechos de Autor; etc.

Actualizada

Poco actualizada

Desactualizada

Obsoleta

* En vías de actualización sería la respuesta en este punto. 
2-La calidad en el sector hotelero se refleja principalmente en (puede elegir hasta 3 opciones):

*En las comodidades del hotel

*En los servicios prestados por el hotel

Por la certificación de calidad del alojamiento

Por la calidez de sus empleados

Por la fidelización del cliente

Por la opinión de especialistas

*Por la opinión de los turistas

La metodología de Categorización en la actualidad depende de la legislación de cada Provincia o Municipio. Fue concebida originalmente como un elemento que apunta al tema Estructural y Edilicio en general y al tipo de Servicios ofrecidos en el mismo. No contempla las características y necesidades de la actualidad, si bien en algunas provincias se ha aggiornado un poco, como ser en Mendoza, y el trabajo que se viene realizando en la CABA pero que aún no ha dado sus frutos.

3- Los clientes relacionan calidad de servicio mayoritariamente con:

*Grande cadenas hoteleras

* Hoteles boutiques

- Pequeños hoteles zonales

- Albergues alternativos

4- Evalúe del 1 al 10, considerando el 1 como la menor conformidad y el 10 como la mayor aceptación a las siguientes afirmaciones:

La legislación hotelera abarca todos los aspectos del alojamiento actual conforme a las exigencias del turismo. (6)

La legislación se adecua a la calidad de prestación del sector. (4) 
La legislación hotelera debe ser reformada en su totalidad. (6)

En la legislación tiene ausente temas que deberían figurar en su redacción.

(6)

La legislación no refleja la realidad local, provincial y nacional. (5/6)

La legislación no debe ser reformada. (1)

5- La certificación en procesos de calidad en turismo son:

* Muy importantes

Algo importantes

Poco importantes

No importan

6- ¿Su organización cuenta con procesos de manejo de quejas y reclamos?

Hay procesos de tratamiento establecido y seguimiento de acciones.

Hay algunos procesos para casos importantes.

Hay pautas para resolver los casos más importantes.

No hay.

Dependiendo el tipo de organización Hotelera, su (Tamaño, Características propias, etc.) se pueden dar entre los primeros tres conceptos, entendiendo que nuestra entidad representada los Hoteles de Alta Gama, por ende la mayoría se posicionaría entre el punto 1 y el 2 .

7- Mejorar la calidad depende de (puede elegir hasta 3 opciones)

- * Las regulaciones y ordenanzas

- * Los procesos

- La inversión en infraestructura

- La actitud de los empleados 
- * La certificación

- La selección y el entrenamiento de los empleados

\section{Anexo II: Encuesta al Sector hotelero para Tesis}

Funcionario del Ministerio de Turismo de la Nación Dr Aramburu, Santiago

1-La legislación se encuentra:

Actualizada

Poco actualizada X

Desactualizada

Obsoleta

2-La calidad en el sector hotelero se refleja principalmente en (puede elegir hasta 3 opciones):

En las comodidades del hotel

En los servicios prestados por el hotel

Por la certificación de calidad del alojamiento

Por la calidez de sus empleados

Por la fidelización del cliente

Por la opinión de especialistas

Por la opinión de los turistas $\mathrm{X}$

3- Los clientes relacionan calidad de servicio mayoritariamente con:

- Grande cadenas hoteleras X

- Hoteles boutiques

- Pequeños hoteles zonales

- Albergues alternativos 
4- Evalúe del 1 al 10, considerando el 1 como la menor conformidad y el 10 como la mayor aceptación a las siguientes afirmaciones

La legislación hotelera abarca todos los aspectos del alojamiento actual conforme a las exigencias del turismo $\mathbf{3}$

La legislación se adecua a la calidad de prestación del sector $\mathbf{3}$

La legislación hotelera debe ser reformada en su totalidad No 2

En la legislación tiene ausente temas que deberían figurar en su redacción

\section{8}

La legislación no refleja la realidad local, provincial y nacional 5

La legislación no debe ser reformada 5

5- La certificación en procesos de calidad en turismo son:

Muy importantes

Algo importantes

Poco importantes

No importan

6- ¿Su organización cuenta con procesos de manejo de quejas y reclamos?

Hay procesos de tratamiento establecido y seguimiento de acciones $\mathrm{X}$

Hay algunos procesos para casos importantes

Hay pautas para resolver los casos más importantes

No hay

7- Mejorar la calidad depende de (puede elegir hasta 3 opciones)

- Las regulaciones y ordenanzas X

- Los procesos 
- La inversión en infraestructura

- La actitud de los empleados X

- La certificación

- La selección y el entrenamiento de los empleados X 